\title{
Characterizing Positive Pressure Ventilation using Computational Fluid Dynamics
}

Stephen Kerber

William D. Walton
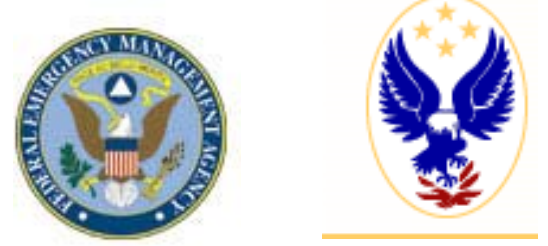

Sponsored in

part by

Federal Emergency

Management Agency

U.S. Fire Administration 


\title{
Characterizing Positive Pressure Ventilation using Computational Fluid Dynamics
}

\author{
Prepared for \\ U.S. Department of Commerce \\ Building and Fire Research Laboratory \\ National Institute of Standards and Technology \\ Gaithersburg, MD 20899-8661
}

Stephen Kerber

William D. Walton

February 2003
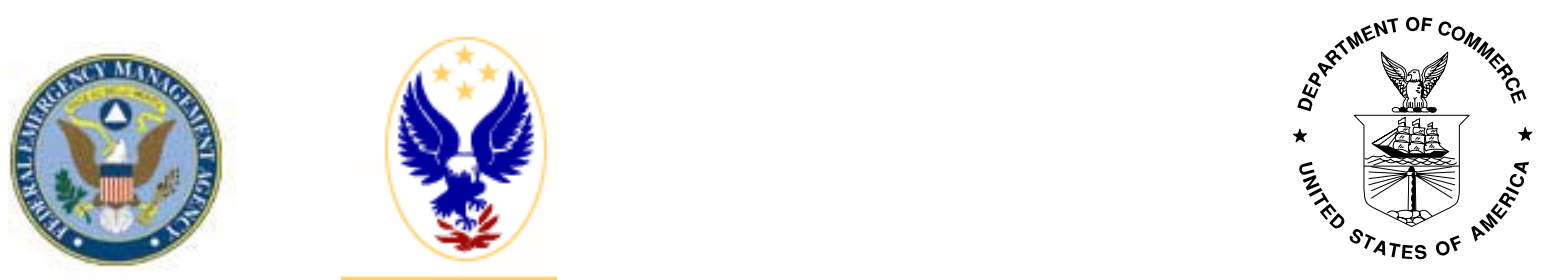

Federal Emergency Management Agency

U.S. Department of Commerce Joe M. Allbaugh , Director

Donald L. Evans, Secretary

U.S. Fire Administration

R. David Paulison, Administrator

Technology Administration

Phillip J. Bond, Under Secretary for Technology National Institute of Standards and Technology Arden L. Bement, Jr., Director 


\section{Table of Contents}

List of Tables ................................................................... iv

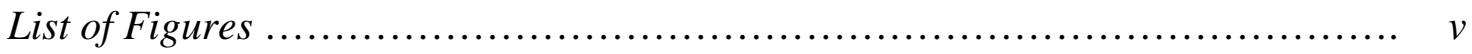

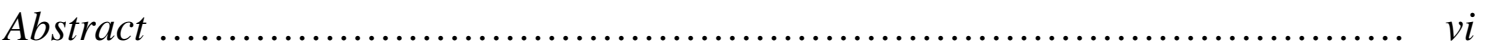

1. INTRODUCTION ................................................ 1

1.1. What is Positive Pressure Ventilation? ........................... 1

2. MAPPING PPV VELOCITY FIELD - PHASE I ................... 2

2.1. Experimental Description ..................................... 2

2.1.1. Experimental Facility ................................. 2

2.1.2. Experimental Components .............................. 2

2.1.3. Experimental Procedure............................... 4

2.1.4. Flow Visualization Experiment ......................... 5

2.2. $\quad$ Computer Model ............................................. 6

2.2.1. Fire Dynamic Simulator ................................. 6

2.2.1a Model Uncertainty ............................. 6

2.2.2. Smokeview .......................................... 7

2.2.3. FDS Input ........................................ 7

2.2.3a Geometry and Vents ........................... 7

2.3. $\quad$ Results ................................................. 9

3. SINGLE ROOM EXPERIMENT - PHASE II ..................... 13

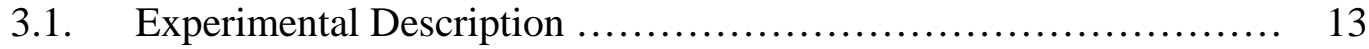

3.1.1. Experimental Facility ................................ 13

3.1.2. Experimental Components ............................. 13

3.1.3. Experimental Layout ................................. 14

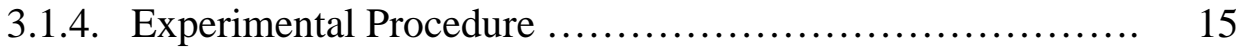

3.1.5. Flow Visualization Experiment ........................ 16

3.2. Computer Model .............................................. 17

3.2.1. FDS Input ....................................... 17

3.2.1a Geometry and Vents .......................... 17

3.3. Results ............................................... 19

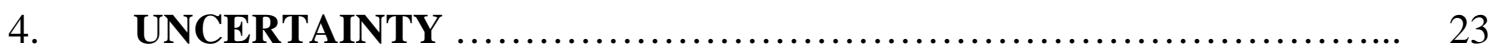

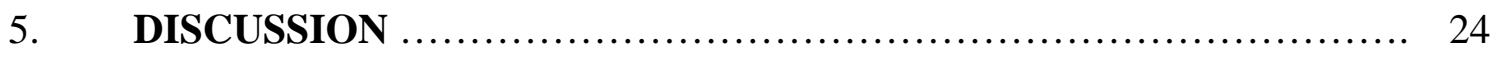

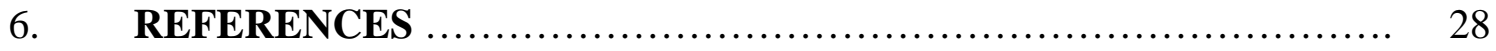

7. ACKNOWLEDGMENTS ...................................... 28 


\section{List of Tables}

Table 1. Comparison of Phase I Experimental and FDS Results .................... 9

Table 2. Comparison of Phase II Experimental and FDS Results................... 19

Table 3. Uncertainty in Experimental Data $\quad 23$

Table 4. Summary of FDS Fan Characteristics Needed to Create an Accurate Flow... 24

Table 5. Summary of Multiblock Characteristics Needed to Create an Accurate Flow.. 24 


\section{List of Figures}

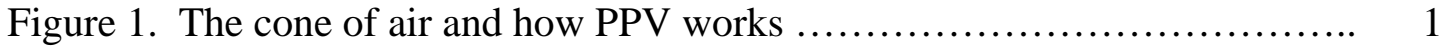

Figure 2. The flow characterization grid ................................. 2

Figure 3. Flow visualization threads on felt background ...................... 2

Figure 4. Front and back of the positive pressure fan ....................... 3

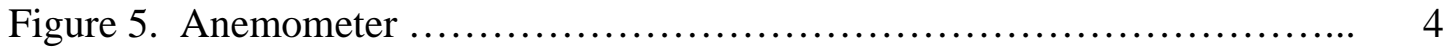

Figure 6. Anemometer in indexer on track ................................. 4

Figure 7. Phase I experimental layout .................................... 4

Figure 8. Phase I measurement points .................................... 5

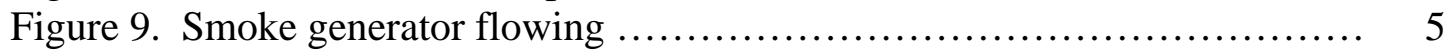

Figure 10. Layout for phase I supplemental test ........................... 5

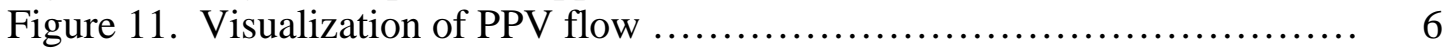

Figure 12. Fan and smoke generator in Phase I visualization test ................ 6

Figure 13. FDS layout visualized with smokeview ......................... 8

Figure 14. Fine grid cell visualization used for computations ................. 8

Figure 15. FDS PPV fan visualized in smokeview .......................... 8

Figure 16. Smokeview visualization of FDS PPV flow pattern ................ 9

Figure 17. Experimental velocities $1830 \mathrm{~mm}(6 \mathrm{ft})$ from the fan ............... 10

Figure 18. FDS velocities $1830 \mathrm{~mm}(6 \mathrm{ft})$ from the fan .................... 10

Figure 19. Experimental velocities $2440 \mathrm{~mm}(8 \mathrm{ft})$ from the fan ............... 11

Figure 20. FDS velocities $2440 \mathrm{~mm}(8 \mathrm{ft})$ from the fan ...................... 11

Figure 21. Experimental velocities $3050 \mathrm{~mm}(10 \mathrm{ft})$ from the fan ............... 12

Figure 22. FDS velocities $3050 \mathrm{~mm}(10 \mathrm{ft})$ from the fan .................... 12

Figure 23. Floor plan of Phase II room ................................ 13

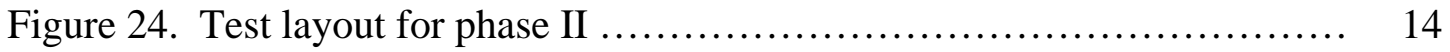

Figure 25. Test layout looking at room inlet and outlet ...................... 14

Figure 26. Inlet and outlet from a different perspective ....................... 15

Figure 27. Phase II measurement points in the doorway (inlet) ............... 15

Figure 28. Phase II measurement points in the window (outlet) ................ 16

Figure 29. Visualization of Phase II supplemental experiment as soon

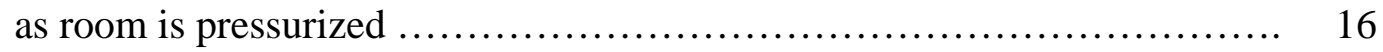

Figure 30. Visualization of Phase II once constant flow is achieved ............ 17

Figure 31. FDS layout for Phase II .................................... 18

Figure 32. Grid cell visualization, multiblocking .......................... 18

Figure 33. FDS layout looking at room inlet and outlet ..................... 19

Figure 34. FDS layout with fan operating .............................. 20

Figure 35. Orientation of velocity graphs ............................................... 20

Figure 36. Experimental velocity measurements in the doorway (inlet) ......... 21

Figure 37. FDS velocities in the doorway (inlet) ........................... 21

Figure 38. Experimental measurements in the window (outlet) ................. 22

Figure 39. FDS velocities in the window (outlet) ......................... 22

Figure 40. Smokeview visualization of FDS PPV flow pattern ................ 23

Figure 41. Experimental visualization of the PPV flow pattern ................ 23

Figure 42. FDS visualization of Phase II supplemental experiment as soon as the

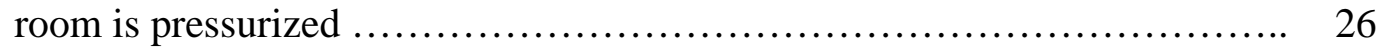

Figure 43. Visualization of Phase II supplemental experiment as soon as the

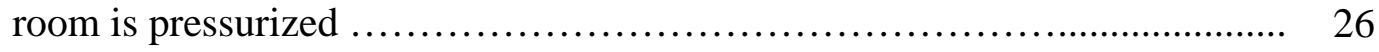

Figure 44. FDS visualization of Phase II once constant flow is achieved ........ 27

Figure 45. Visualization of Phase II once constant flow is achieved ............. 27 


\title{
Characterizing Positive Pressure Ventilation using Computational Fluid Dynamics
}

\author{
Stephen Kerber \\ William D. Walton
}

\begin{abstract}
Data from two different sets of full-scale experiments are compared with simulations completed with the computational fluid dynamic model, the Fire Dynamic Simulator (FDS). The full-scale experiments characterize a Positive Pressure Ventilation (PPV) fan in an open atmosphere and in a simple room geometry. The measurements of both experiments compare favorably with the Fire Dynamic Simulator results. With the correct geometry, vent placement, and boundary location FDS predicted velocities that were within 10 percent for the open atmosphere and 20 percent for the simple room geometry. FDS's visualization of the positive pressure ventilation fan's flow pattern, and the flow out of the window also correlated well with those measured experimentally.
\end{abstract}

\section{Disclaimer}

Certain trade names and company products are mentioned in the text or identified in an illustration in order to specify adequately the experimental procedure and equipment used. In no case does such identification imply recommendation or endorsement by the National Institute of Standards and Technology, nor does it imply that the products are necessarily the best available for the purpose. 


\section{INTRODUCTION}

This research effort used a series of full-scale experiments to examine how positive pressure ventilation (PPV) may impact structural ventilation. These same experiments were simulated using the NIST Fire Dynamics Simulator (FDS) to provide more insight into the impact of ventilation on fire behavior. Comparing the computer simulations with the full-scale test results allows the computer simulation to be validated and if necessary, identifies areas that need improvement. Ultimately, using computer models to simulate the effects of PPV could be used to improve fire fighter safety by enabling improved understanding of structural ventilation techniques.

PPV fans are engineered to maximize airflow while allowing the fan to remain light and durable for fire service use. Simply, a blade or impeller pulls air through a shroud creating the airflow. This blade or impeller is driven by an electric or gasoline motor all of which are mounted in a frame. The velocity field that is created is complex due to the speed at which the blade or impeller rotates to achieve a conical flow. These experiments examine FDS's ability to accurately characterize this complex flow.

This work will lead to a better understanding of the effective use of ventilation and the development of guidelines for the most effective use of positive pressure ventilation, including when it should and should not be used. These are both concerns that the fire service has documented in reference [1].

\subsection{What is Positive Pressure Ventilation?}

Positive pressure ventilation is a technique used by the fire service to remove smoke, heat and other combustion products from a structure. This allows the fire service to perform other tasks in a more tenable atmosphere. Typically a positive pressure ventilation fan is

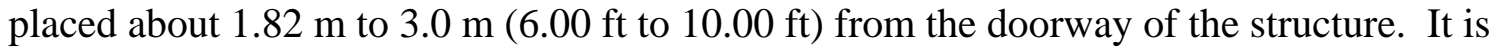
positioned so that the "cone of air" produced by the fan extends beyond the boundaries of the opening. With the doorway within the fan discharge, air pressure inside the structure increases. An exhaust opening in the structure, such as an opening in the roof or an open window, allows the air to escape due to the difference between the inside and outside air pressure. The smoke, heat and other combustion products are pushed out of the structure and replaced with fresh air [2].

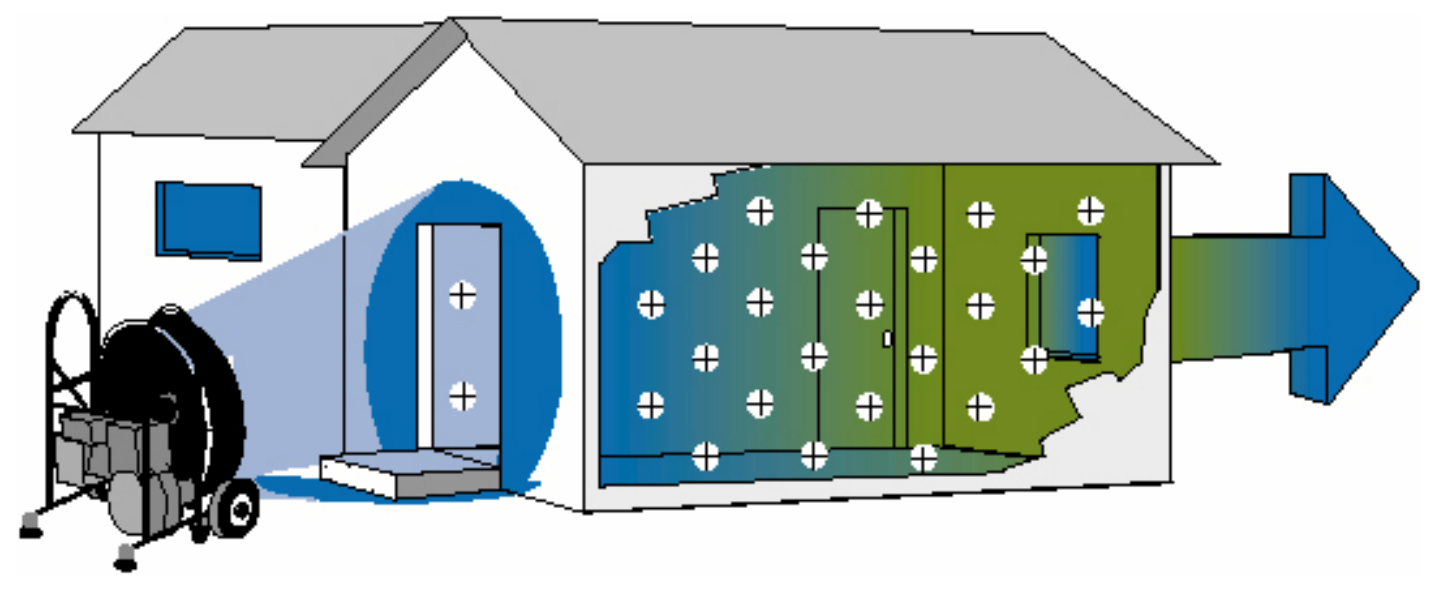

Figure 1. The cone of air and how PPV works [3]. 


\section{MAPPING PPV VELOCITY FIELD - PHASE I}

\subsection{Experimental Description}

The initial series of experiments served to determine the flow created by PPV fans. In order to implement a PPV fan in FDS it was necessary to characterize the fan in terms of FDS input parameters. This basic environment was an open atmosphere with the fan located on a stand that had negligible effects on the flow, essentially placing the fan in open space. This placement minimized the impact from obstructions such as walls and doorways on the flow.

\subsubsection{Experimental Facility}

These experiments were conducted at NIST's Building and Fire Research Laboratory Large Fire Facility. The experiment was located in an area inside the facility so that the airflow created by the PPV fan was not affected by external factors such as wind or

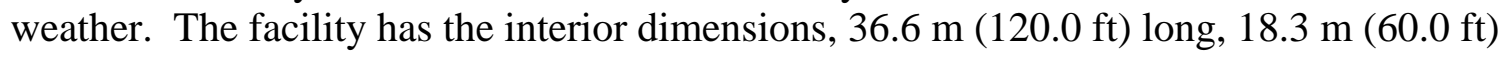
wide and $7.6 \mathrm{~m}(25.0 \mathrm{ft})$ high.

\subsubsection{Experimental Components}

\section{Grid}

A grid frame, $2.44 \mathrm{~m}$ x $2.44 \mathrm{~m}$ (8.00 ft x $8.00 \mathrm{ft}$ ), was constructed with $51 \mathrm{~mm}$ x $102 \mathrm{~mm}$ ( 2.00 in $x 4.00$ in) wood members a square configuration. The corners were reinforced with plywood triangles. Cotton strings approximately $1.6 \mathrm{~mm}$ (0.0625 in) in diameter were placed on the grid both vertically and horizontally marking points on the grid. The center was highlighted by using orange string, while white strings were placed every 102 $\mathrm{mm}$ (4.00 in) for the first $305 \mathrm{~mm}$ (12.00 in) then every $152 \mathrm{~mm}$ (6.00 in) towards the edge of the frame in both directions. The frame was notched to keep the strings in place (Figure 2). Once the strings were all in place, $203 \mathrm{~mm}$ (8.00 in) long threads were added to each point on the grid. These threads made it possible to view the direction of airflow (Figure 3). Finally, black felt was added to the frame, parallel to the threads in order to give a contrasting background to the threads to aid in flow visualization. The felt did not appear to have a significant impact on the measured flow.

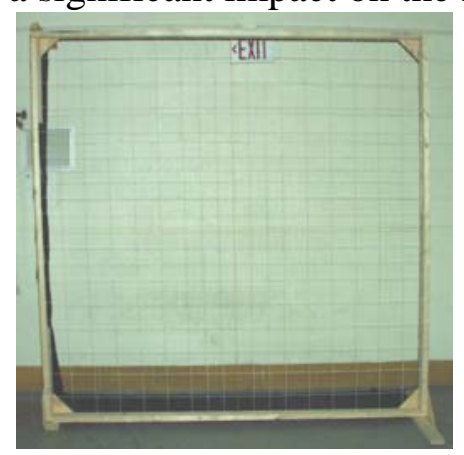

Figure 2. The grid.

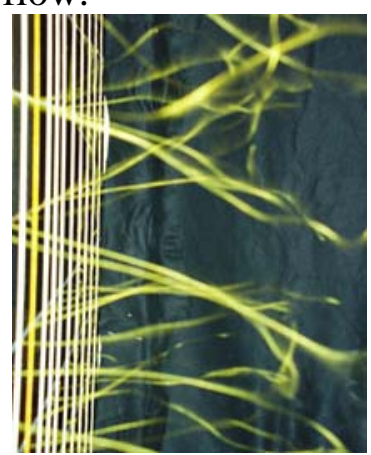

Figure 3. Threads on felt background. 


\section{Fan}

The fan used was an 18-inch, variable speed, electric positive pressure ventilator. The fan has a depth of $476 \mathrm{~mm}$ (18.8 in), width of $622 \mathrm{~mm}$ (24.5 in) and height of $622 \mathrm{~mm}$ (24.5 in). It has a maximum speed of 2200 RPM, a rating of 746 watts (1 hp) and a rating of $6.64 \mathrm{~m}^{3} / \mathrm{s}\left(14,060 \mathrm{ft}^{3} / \mathrm{min}\right)$. The fan was mounted on a stand to set the fan at the proper height of $1.28 \mathrm{~m}$ (50.5 in), measured from the center of the fan to the ground (Figure 4). The grid was positioned so that the center of the fan impeller was on the centerline of the grid.

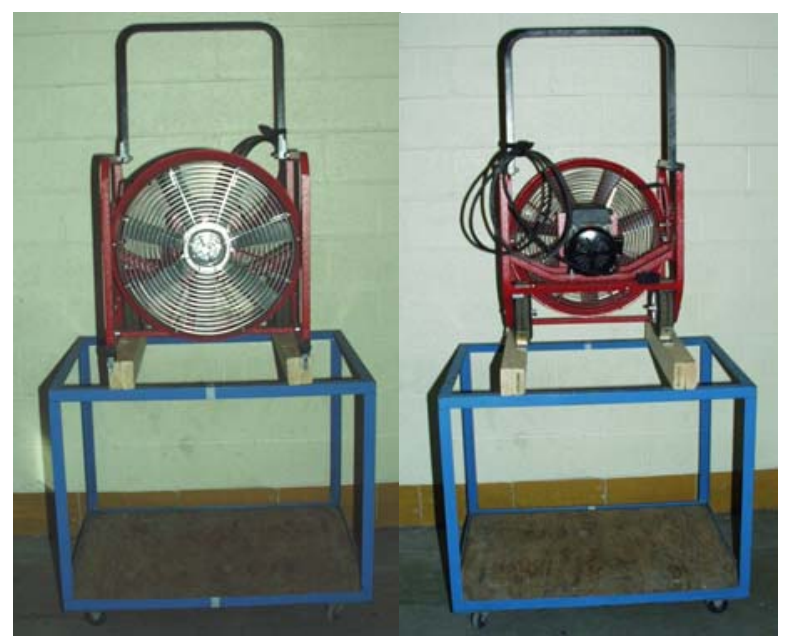

Figure 4. Front and back of the positive pressure fan and stand.

\section{Anemometer}

The digital anemometer used was a $25.4 \mathrm{~mm}$ (1.00 in) diameter vane-type probe (Figure 5). It is microprocessor-based with a range of $0.3 \mathrm{~m} / \mathrm{s}(59 \mathrm{ft} / \mathrm{s})$ to $35.0 \mathrm{~m} / \mathrm{s}(6890 \mathrm{ft} / \mathrm{m})$ with an accuracy of $0.5 \%$ of the readings [4]. In order to position the anemometer at various locations, an anemometer indexer was fabricated. The indexer allowed the anemometer to be placed at any point on the grid by moving it horizontally and vertically. The indexer also permitted the anemometer to rotate in both the $\mathrm{x}$ and $\mathrm{y}$-axis. This rotation allowed the measurement of velocities that were not parallel to the ground and perpendicular to the fan. The indexer moved horizontally across the grid on wheels that were grooved to ride an angle iron track. This track was positioned on the ground parallel with the grid (Figure 6). 


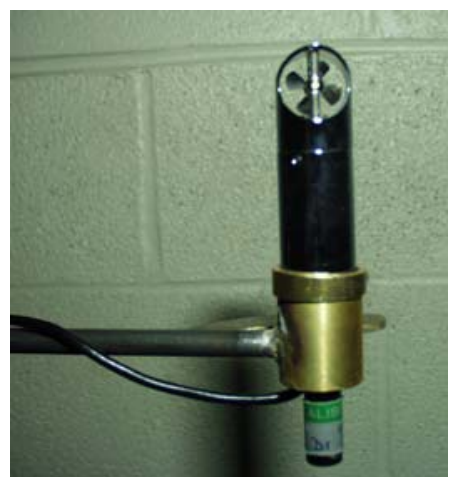

Figure 5. Anemometer.

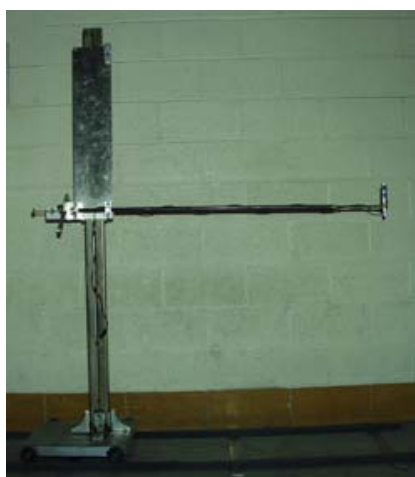

Figure 6. Anemometer in indexer on track.

\subsubsection{Experimental Procedure}

The grid and track were placed perpendicular to the flow. The fan was positioned so that the flow was centered on the grid $1.28 \mathrm{~m}$ (50.5 in) above the floor. The anemometer indexer was moved along the track and its height adjusted to correspond with measurement positions on the grid. (Figure 7) The vane of the anemometer was maintained perpendicular to the flow. The fan was started and run for two minutes at the maximum speed of $2200 \mathrm{rpm}$. The anemometer output was recorded every two seconds for four minutes using 16 second averaging. This process was repeated for the selected points on the grid shown in figure 8.

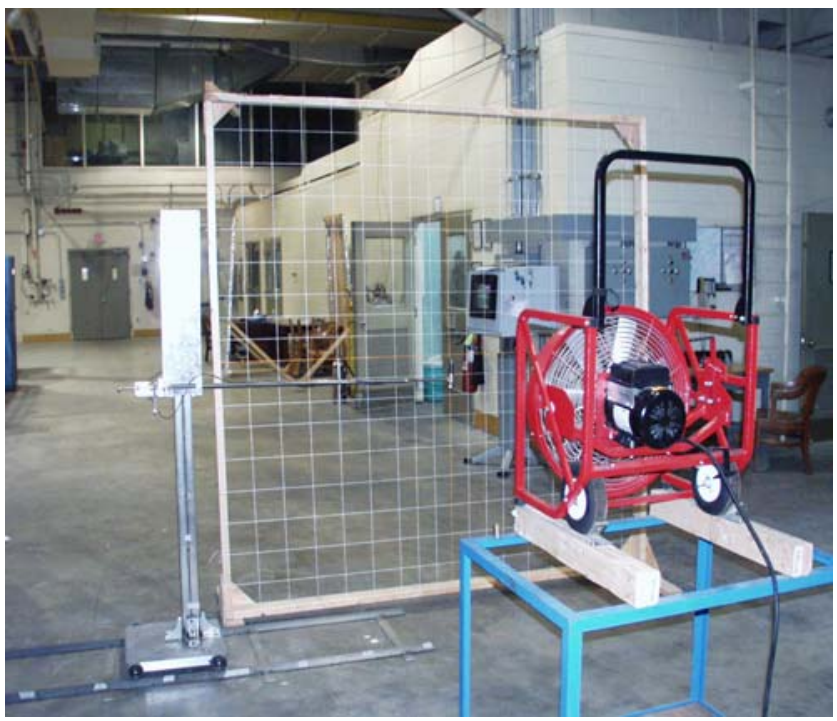

Figure 7. Phase I experimental layout. 


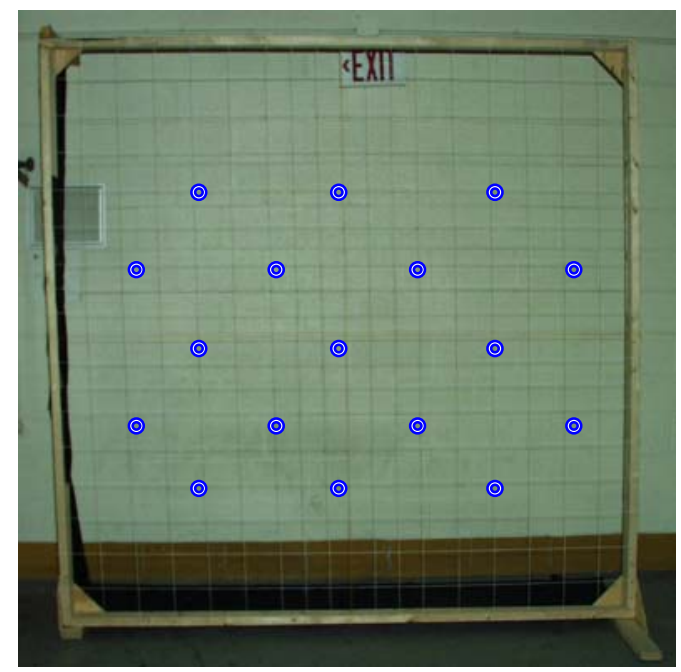

Figure 8. Phase I measurement points.

\subsubsection{Flow Visualization Experiment}

In order to visualize and qualify the flow from the fan a supplemental test was performed. A smoke generator was placed $304.8 \mathrm{~mm}(1 \mathrm{ft})$ to the rear of the fan (Figure 12). The fan was turned on $2200 \mathrm{rpm}$ and allowed to warm up. The smoke generator was then turned on to maximum output and pictures were taken against a black background with heights labeled in $304.8 \mathrm{~mm}(1 \mathrm{ft})$ intervals and widths labeled in $609.6 \mathrm{~mm}(2 \mathrm{ft})$ intervals. See figures 9-12.

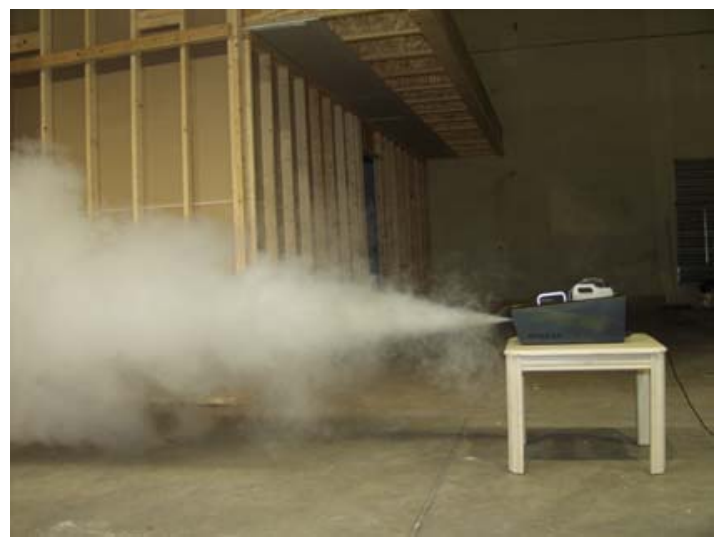

Figure 9. Smoke generator flowing

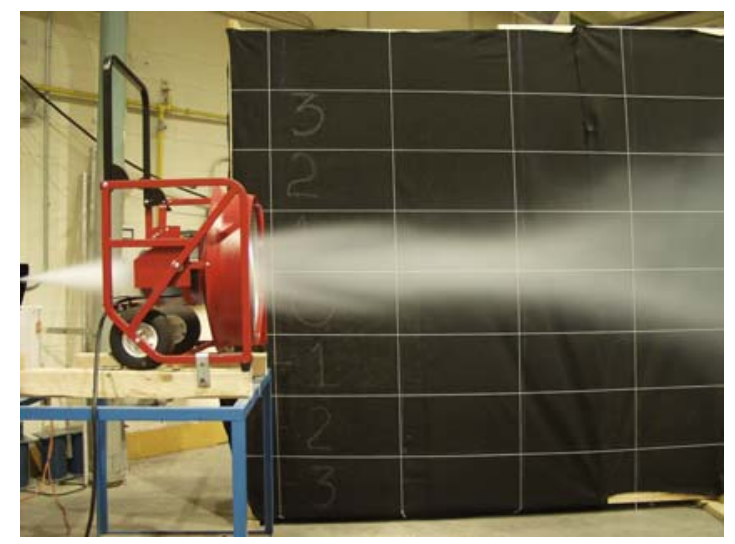

Figure 10. Layout for phase I flow visualization experiment. 


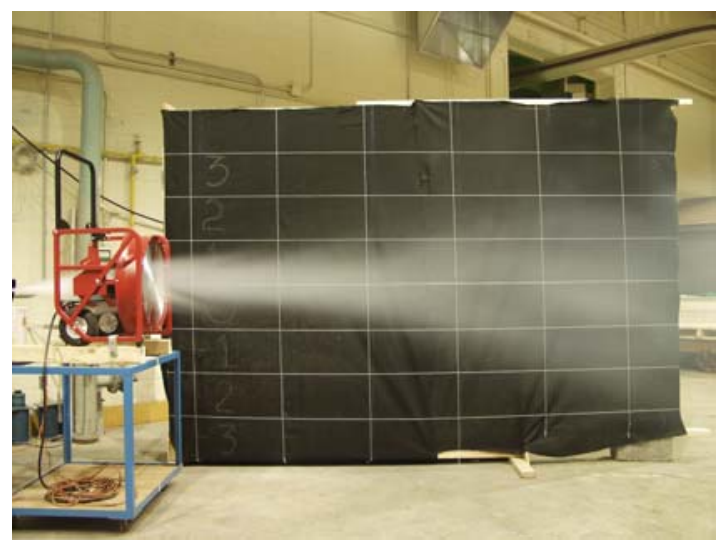

Figure 11. Visualization of PPV flow.

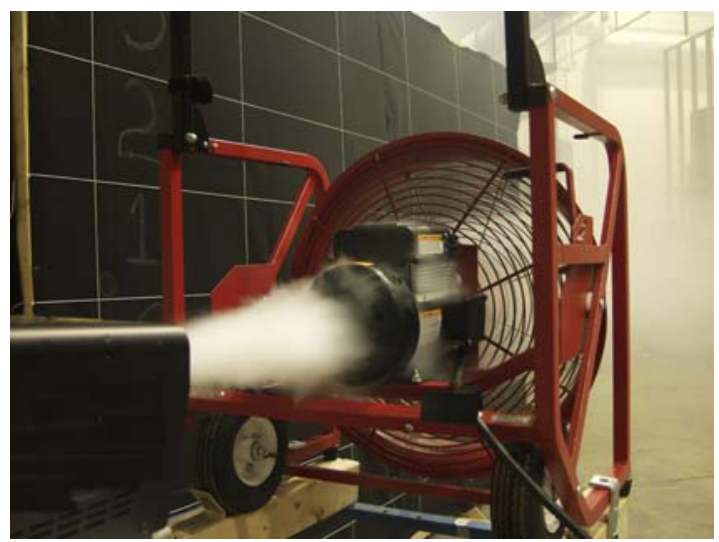

Figure 12. Fan and smoke generator in phase I visualization experiment.

\subsection{Computer Model}

\subsubsection{Fire Dynamic Simulator}

NIST has developed a computational fluid dynamics (CFD) fire model using large eddy simulation (LES) techniques [5]. This model, called the NIST Fire Dynamics Simulator (FDS), Version 3.0, has been used to simulate the flame spread, temperatures and gas flows resulting from a compartment fire [6]. A CFD model requires that the room, building or atmosphere of interest be divided into three-dimensional rectangular control volumes or computational cells. The CFD model computes the density, velocity, temperature, pressure, and species concentration of the gas in each cell. Based on the laws of conservation of mass, momentum, species and energy the model tracks the generation and movement of gases. FDS utilizes material properties of the furnishings, walls, floors, and ceilings to compute fire growth and spread. A more complete description of the FDS model is provided in reference [5].

\subsection{1a Model Uncertainty}

FDS can provide valuable insight into how a fire may develop or how the combustion gases will move throughout the structure. However the model is only a simulation. The model output is dependent on a variety of input and default values such as computational cell size, material properties, geometry, and vents.

The ability of the FDS model to accurately predict the temperature and velocity of fire gases has been previously evaluated by conducting experiments, both lab-scale and fullscale, and measuring quantities of interest. For relatively simple fire driven flows, such as buoyant plumes and flows through doorways, FDS predictions are within the experimental uncertainty of the values measured in the experiments [7]. For example, if a gas flow velocity is measured at $0.5 \mathrm{~m} / \mathrm{s}$ with an experimental uncertainty of \pm 0.05 $\mathrm{m} / \mathrm{s}$, the FDS model gas flow velocity predictions were also within the range between $0.45 \mathrm{~m} / \mathrm{s}$ and $0.55 \mathrm{~m} / \mathrm{s}$.

In large-scale fire tests reported in [6], FDS temperature predictions were found to be within $15 \%$ of the measured temperatures and the FDS heat release rates were predicted 
to within $20 \%$ of the measured values. Therefore the results are presented as ranges to address these uncertainties.

These experiments attempt to prove that using the correct set of inputs; FDS is able to model the flows of positive pressure ventilation fans within a desirable uncertainty.

\subsubsection{Smokeview}

Smokeview is a scientific visualization program that was developed to display the results of a FDS computation. Smokeview can produce animations or snapshots of FDS results [8]. This project used Smokeview to generate a series of planar slices. A slice file allows a user to record various gas phase quantities such as velocity at more than a single point. Each slice can portray a specific set of data, such as gas temperature or gas velocity for each location on that slice plane. Smokeview allows the user to animate a series of slices to help visualize how the data develops or changes throughout the computer model simulation. A series of temperature slices can be replayed to see how the temperature profiles develop along a specific plane in a structure. Figure 16 shows a vertical slice file along the center of the domain.

\subsubsection{FDS Input}

Inputs required by FDS in order to model PPV fans include, domain size, computational cell size, simulation duration, vent velocity, vent geometry, fan geometry, slice location and velocity measurement points. Many inputs were used for preliminary FDS runs, which are explained in the following sections.

\subsection{3a Geometry and Vents}

Many considerations need to be taken into account when modeling a PPV fan using FDS. The most important is the computational cell size. The cells need to be on the order of $16.4 \mathrm{~cm}^{3}\left(1.00 \mathrm{in}^{3}\right)$. Once the cells are prescribed greater than $21.3 \mathrm{~cm}^{3}\left(1.10 \mathrm{in}^{3}\right)$ the flow from the fan becomes linear and inaccurate. The cell size in the computation in figures $13-15$ is $16.4 \mathrm{~cm}^{3}\left(1 \mathrm{in}^{3}\right)$. The next consideration is the domain size. There needs to be at least $1 \mathrm{~m}$ ( $3.3 \mathrm{ft})$ to the rear of the fan in order for it to function accurately. If the fan is prescribed at or within $1 \mathrm{~m}(3.3 \mathrm{ft})$ of the boundary, whether it is "open" or not, the fan flow will not be predicted properly. The obstructions and vents that make up the fan itself need to be prescribed correctly. FDS only allows for rectangular obstructions and vents to be created, so this leads to an issue due to the cylindrical nature of the fan shroud. In order to get a proper flow pattern the shroud must be prescribed as a series of obstructions oriented in a circle such as figure 15. The degree of roundness depends on the accuracy that is desired. The shroud in figure 15 yielded good results but the shroud can be created more cylindrical if desired. It is not recommended to further square off the shroud using fewer obstructions.

The vents are prescribed to the interior dimensions of the shroud. They also must be located on the front of the shroud, opposite the motor and handle. This allows air to be pulled through the shroud creating a more realistic flow pattern. If the vents are placed to the rear or middle of the shroud the flow pattern will appear linear and unrealistic. The vents also had a prescribed velocity. Numerous velocities were examined within FDS and the velocity that provided the best result was $17.89 \mathrm{~m} / \mathrm{s}(40.00 \mathrm{mi} / \mathrm{h})$. This input is 
based on maximum speed of the experimental PPV fan. Altering this input allows the user to characterize the fan operating at different speeds. The final items are the obstructions in the center of the fan, simulating the center of the blade connected to the shaft, and the motor and handle to the rear of the shroud. These obstructions were found to create a more realistic flow pattern. They affect the air moving through the shroud in FDS similarly as they did experimentally. Pulling air past the motor affects the flow pattern significantly so it must be included in the model. Finally slice files and prediction points were prescribed. The slice files were placed at the center of the fan in both the horizontal and vertical directions to visualize the flow pattern. Velocity measurement points were placed in the model in conjunction with the measurement points used experimentally, in order to make a good comparison of the two $(1.83 \mathrm{~m}, 2.44 \mathrm{~m}$, and 3.05 $\mathrm{m}$ (6 ft, $8 \mathrm{ft}$ and $10 \mathrm{ft}$ ) from the PPV fan).

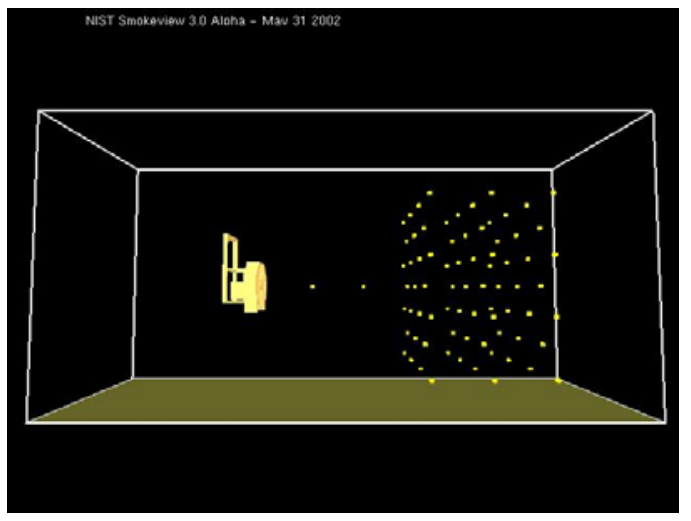

Figure 13. FDS layout visualized with smokeview.

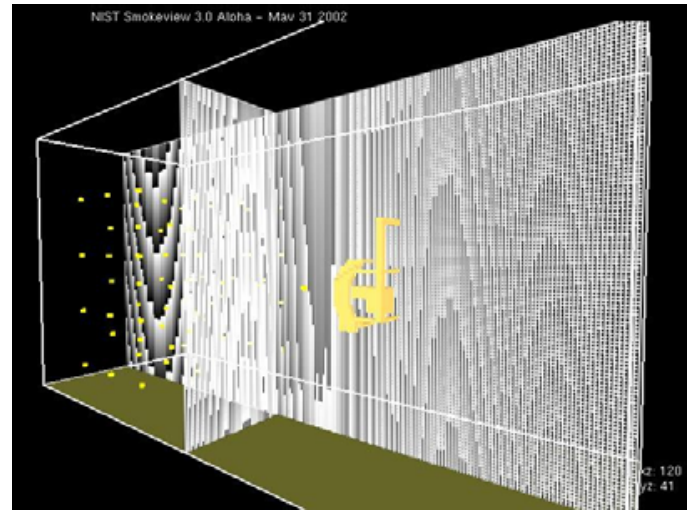

Figure 14. Fine grid cell visualization used for computations.

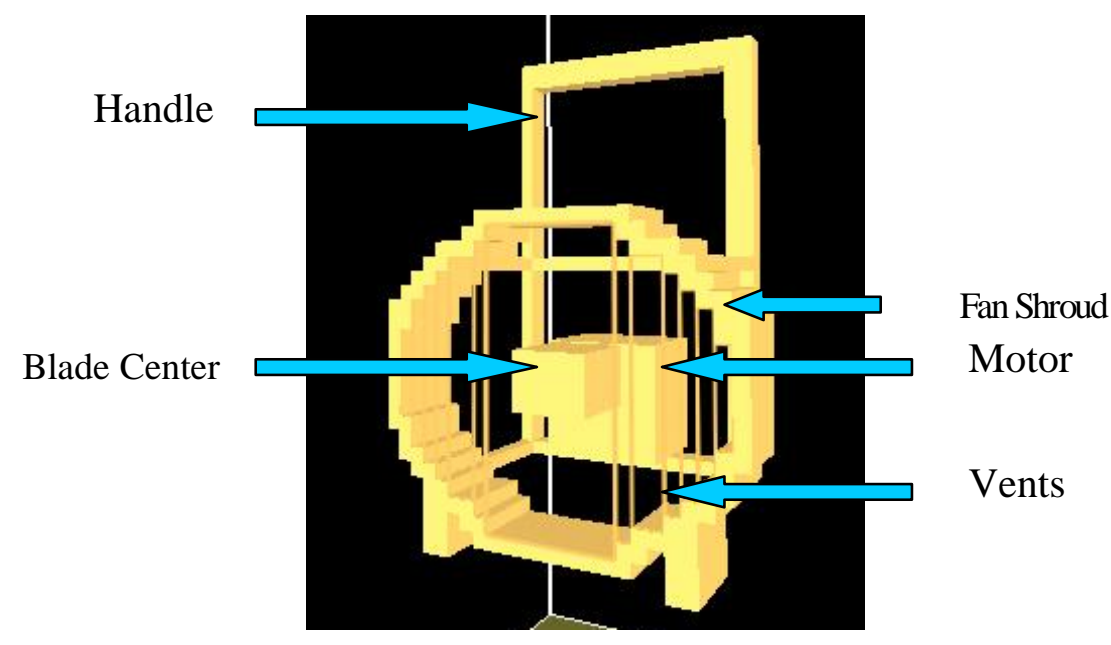

Figure 15. FDS PPV fan visualized in smokeview. 


\subsection{Results}

Velocity measurements were taken at the locations in figure 8. These measurements were recorded with the fan at $1.83 \mathrm{~m}, 2.44 \mathrm{~m}$, and $3.05 \mathrm{~m}$ (6 ft, $8 \mathrm{ft}$ and $10 \mathrm{ft}$ ) from the anemometer, corresponding to typical distances of a positive pressure ventilation fan from a structure. The magnitudes of the velocities are shown in figures 17, 19 and 21. The average velocities of the three distances were $2.42 \mathrm{~m} / \mathrm{s}, 2.72 \mathrm{~m} / \mathrm{s}$ and $3.35 \mathrm{~m} / \mathrm{s}$ (7.90 $\mathrm{ft} / \mathrm{s}, 8.90 \mathrm{ft} / \mathrm{s}$ and $11.00 \mathrm{ft} / \mathrm{s}$ ) respectively. Using NIST's Fire Dynamic Simulator, many runs were performed examining the possibilities of creating a PPV fan that closely portrays the actual fan that was used for experimentation. The final fan that was created and used in the FDS runs, figure 15, yielded velocity measurements that are graphed in figures 18, 20 and 22. The average velocities of the three distances were $2.65 \mathrm{~m} / \mathrm{s}, 3.19$ $\mathrm{m} / \mathrm{s}$ and $3.25 \mathrm{~m} / \mathrm{s}(8.7 \mathrm{ft} / \mathrm{s}, 10.5 \mathrm{ft} / \mathrm{s}$ and $10.7 \mathrm{ft} / \mathrm{s})$ respectively. This comparison gives an average difference of slightly less than $10 \%$. The quality of the flow can be compared in figures 39 and 40 .

Table 1. Comparison of Phase I Experimental and FDS Results.

\begin{tabular}{|l|c|c|c|}
\hline & \multicolumn{3}{|c|}{ Average Velocities (m/s (ft/s)) } \\
\hline Distance To Anemometer & $1830 \mathrm{~mm}(6 \mathrm{ft})$. & $2440 \mathrm{~mm}(8 \mathrm{ft})$. & $3050 \mathrm{~mm}(10 \mathrm{ft})$. \\
\hline Experimental & $2.42(7.9)$ & $2.72(8.9)$ & $3.35(11.0)$ \\
\hline Fire Dynamic Simulator & $2.65(8.7)$ & $3.19(10.5)$ & $3.25(10.7)$ \\
\hline Percent Difference (\%) & 8.7 & 14.7 & 3.1 \\
\hline
\end{tabular}

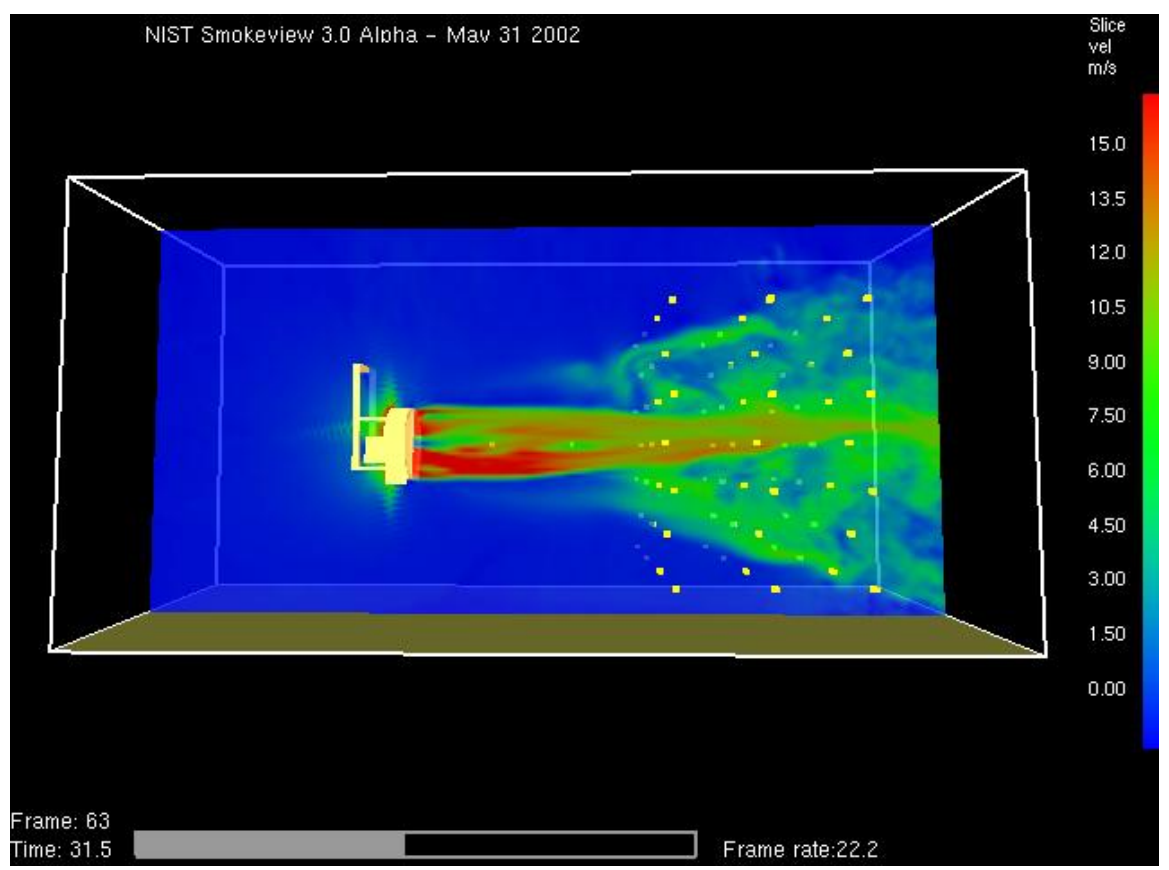

Figure 16. Smokeview visualization of FDS PPV flow pattern. 


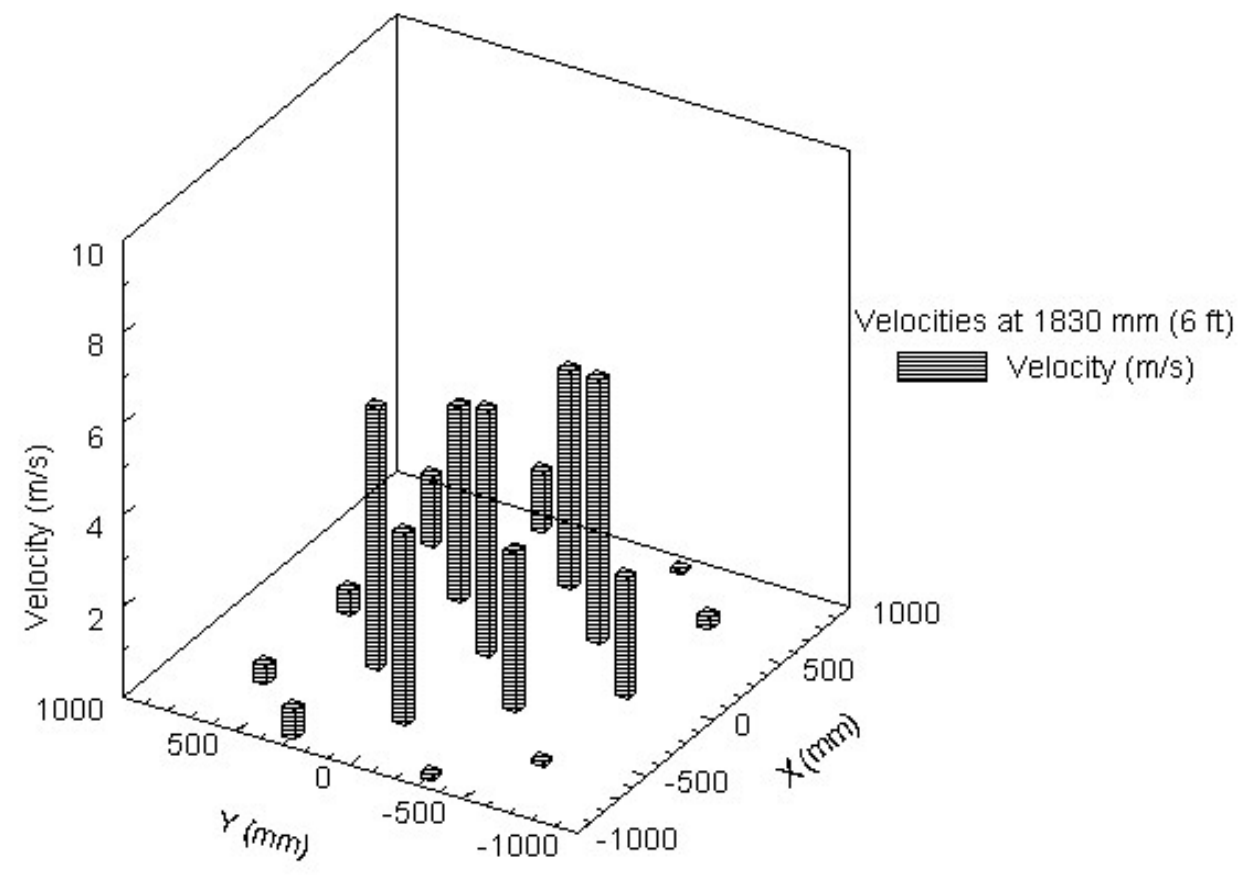

Figure 17. Experimental velocities $1830 \mathrm{~mm}(6 \mathrm{ft})$ from the fan. The center of the fan is located at $(0,0)$.

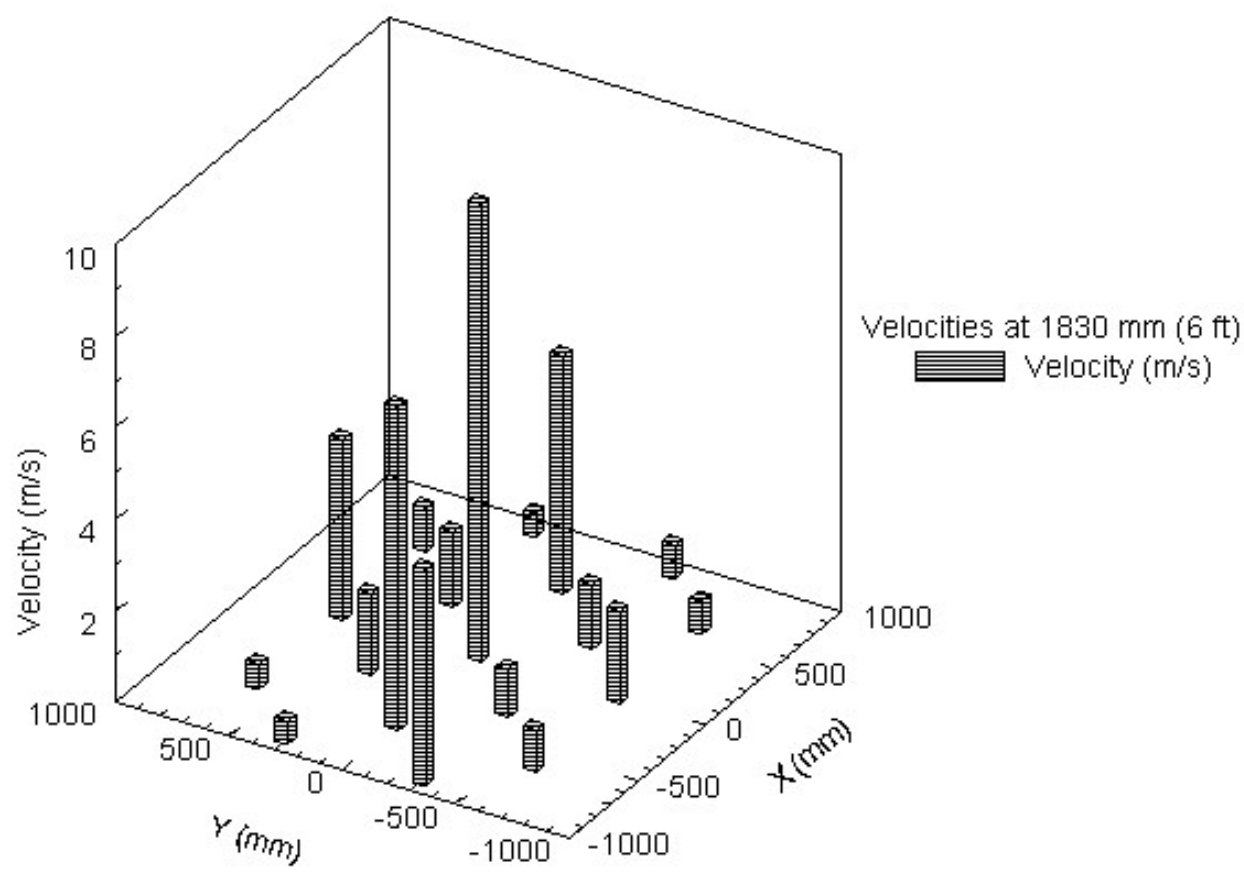

Figure 18. FDS velocities $1830 \mathrm{~mm}(6 \mathrm{ft})$ from the fan. 


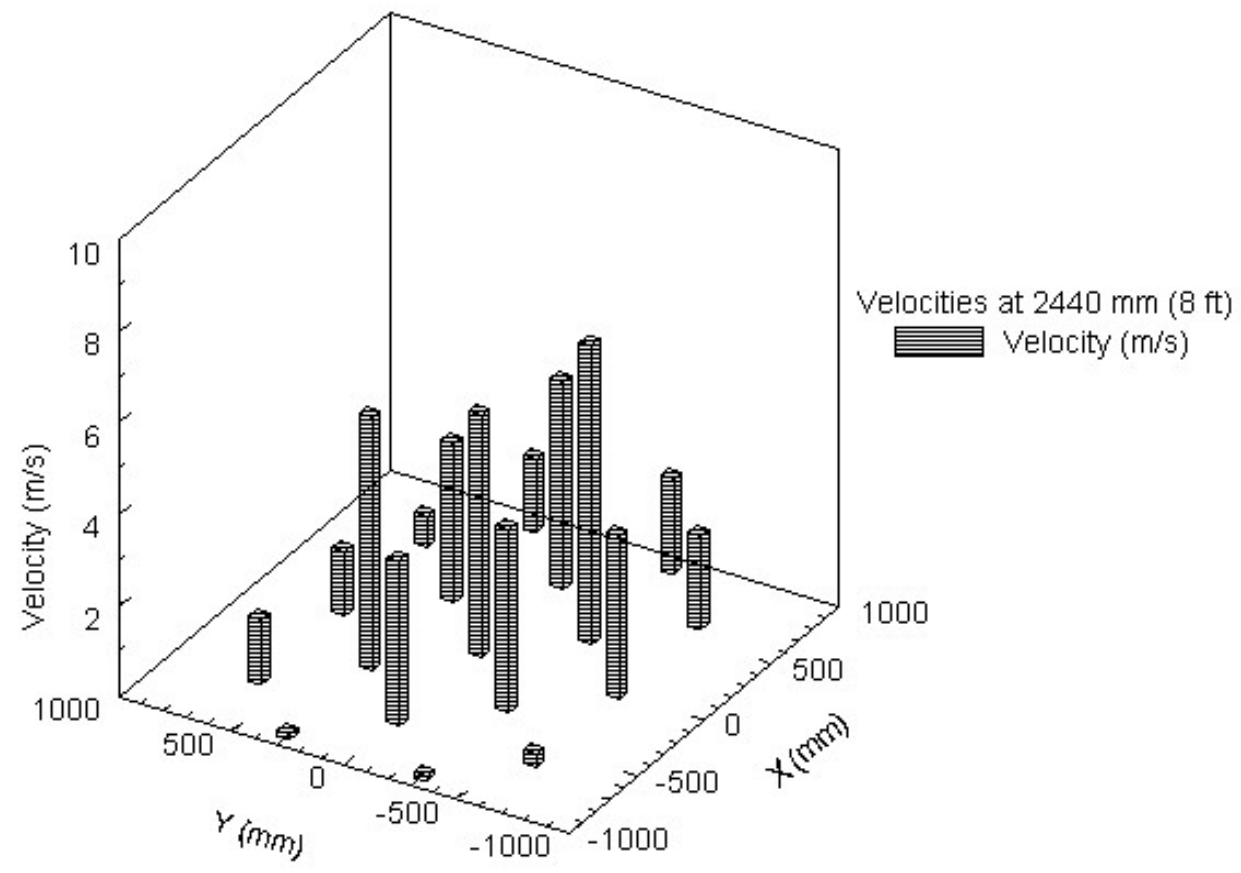

Figure 19. Experimental velocities $2440 \mathrm{~mm}(8 \mathrm{ft})$ from the fan.

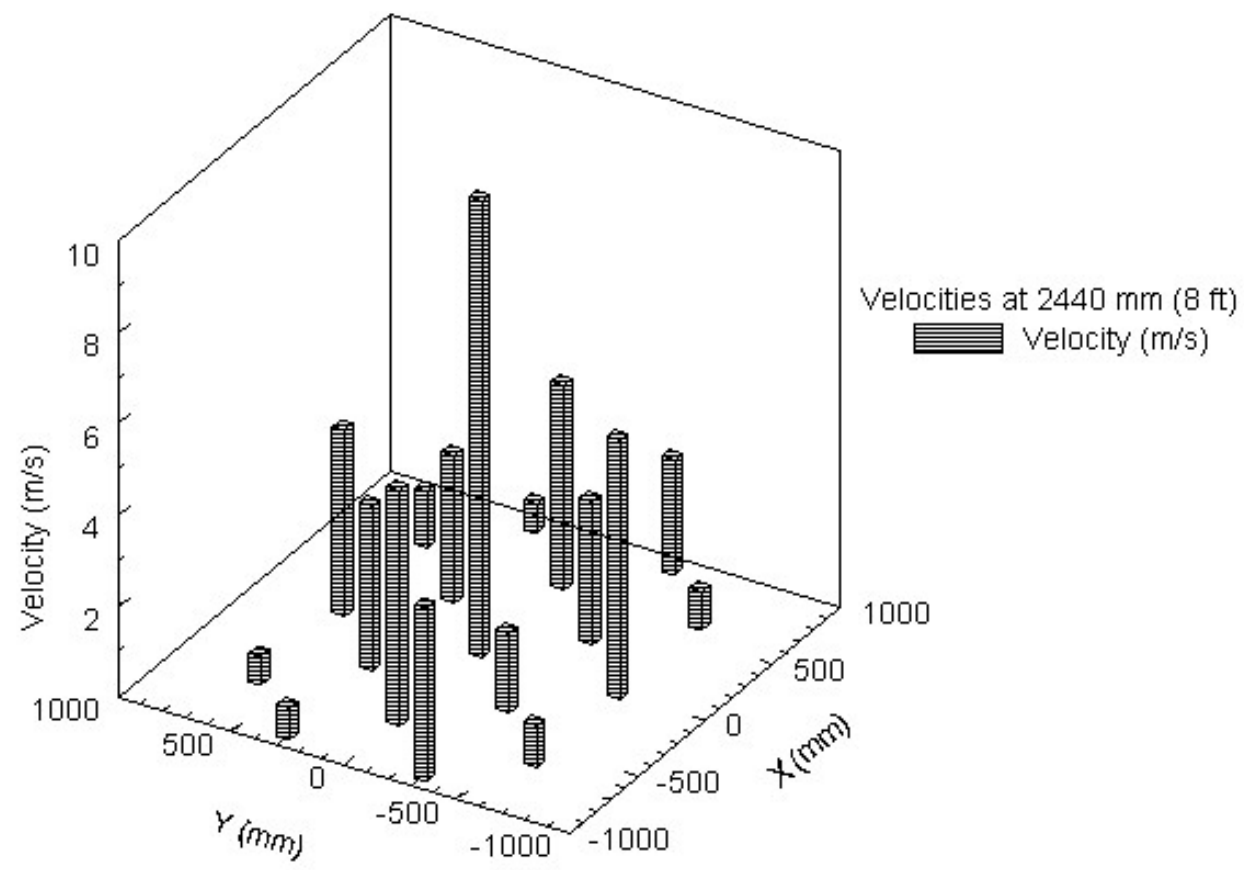

Figure 20. FDS velocities $2440 \mathrm{~mm}(8 \mathrm{ft})$ from the fan. 


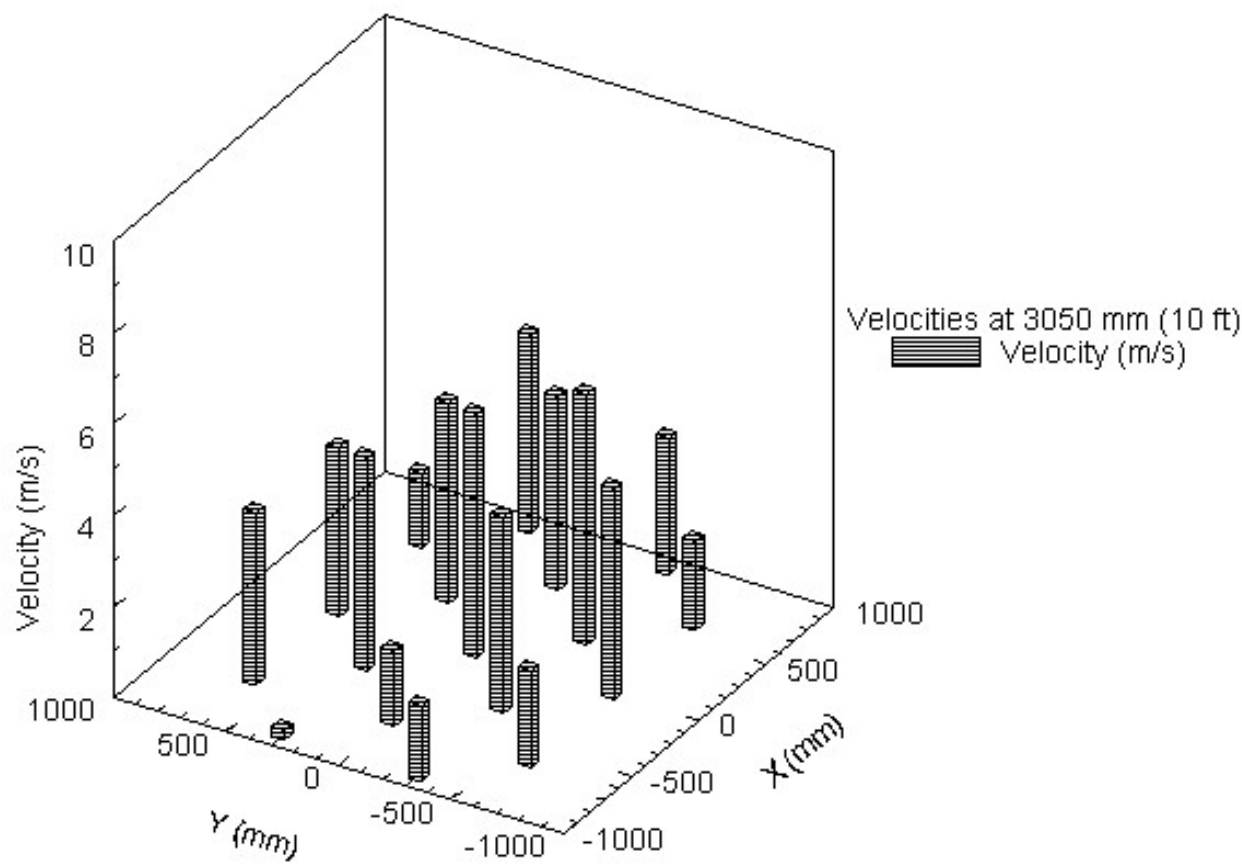

Figure 21. Experimental velocities $3050 \mathrm{~mm}(10 \mathrm{ft})$ from the fan.

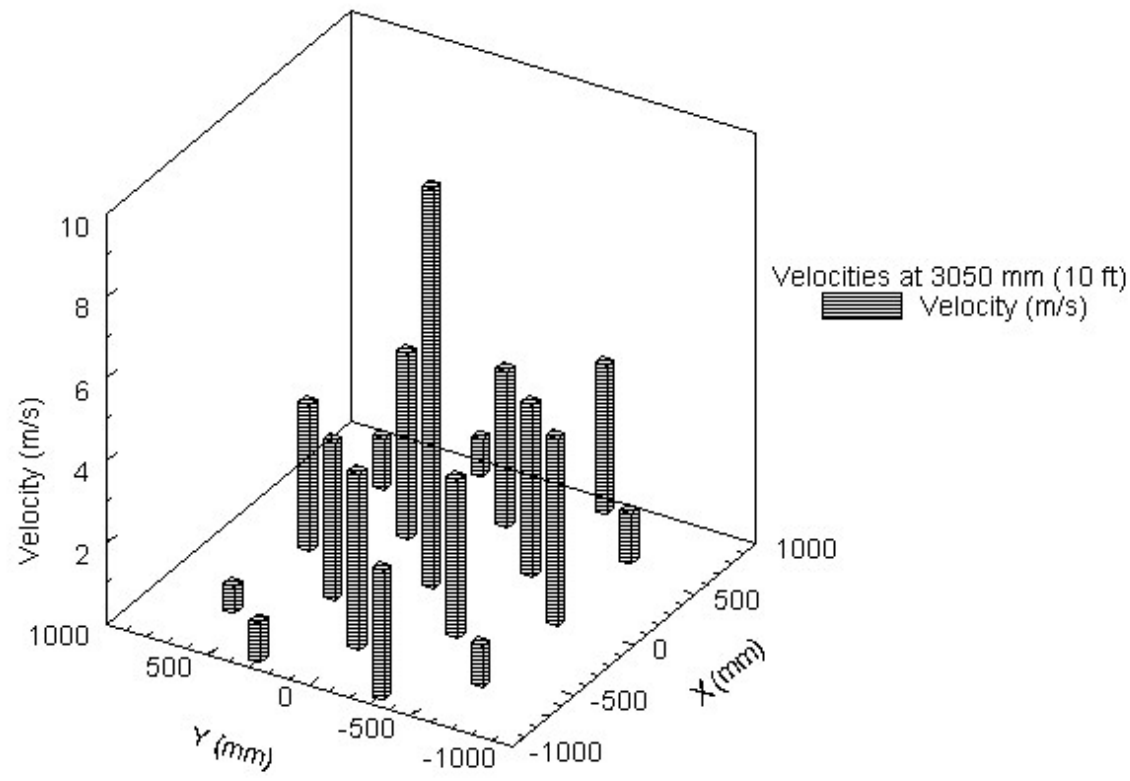

Figure 22. FDS velocities $3050 \mathrm{~mm}(10 \mathrm{ft})$ from the fan. 


\section{SINGLE ROOM EXPERIMENT - PHASE II}

\subsection{Experimental Description}

A series of experiments were conducted to determine the impact that basic room geometries have on the flow of PPV fans. The experimental results were compared to FDS simulations to see if FDS predicts the airflow accurately. Just as in phase I, the results were both qualitative and quantitative.

\subsubsection{Experimental Facility}

These experiments were also conducted at NIST's Building and Fire Research Laboratory Large Fire Facility. The experiment was located in an area within the facility so that the airflow created by the PPV fan was not affected by external factors to the experiments. The facility has the interior dimensions, 36.6 meters $(120 \mathrm{ft})$ long, 18.3 meters $(60 \mathrm{ft})$ wide and 7.6 meters $(25 \mathrm{ft})$ high.

\subsubsection{Experimental Components}

\section{Fan and Anemometer}

The same fan and anemometer were used in phase I and phase II. A complete description can be found in section 2.1.2 of this report.

\section{Room}

The floor plan for the room was shown in figure 23. The room was on a $203 \mathrm{~mm}$ (8 in) high base with a plywood decking and had a ceiling that was 2,640 mm (8 ft - $8 \mathrm{in}$ ) high, measured from the top of the base. The window on the left hand side of the room was located $457 \mathrm{~mm}$ (18 in) off the floor and was 1,372 mm (54 in) tall. The door centered in

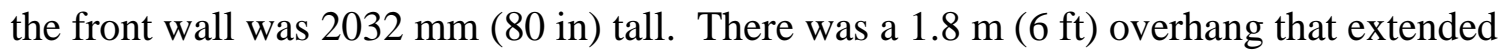
over the front of the room (Figure 26).

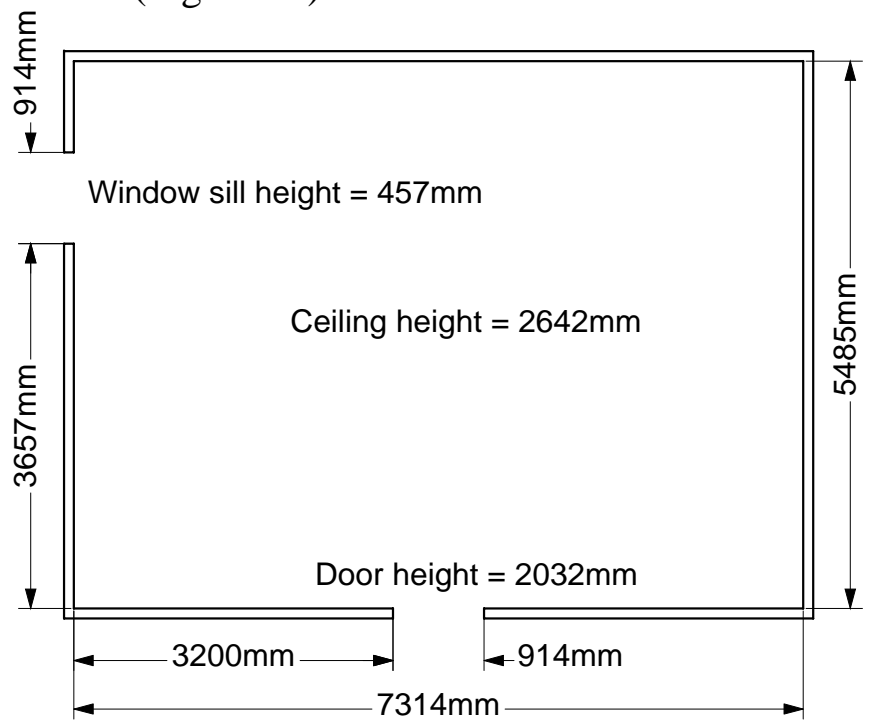

Figure 23. Floor plan of Phase II room. 


\subsubsection{Experimental Layout}

The room was constructed and was not furnished with carpeting or furniture. The fan was positioned in the center of the doorway and allowed to run at maximum rpm. The cone of air coming from the fan covered the doorway when the fan was $3050 \mathrm{~mm}(10 \mathrm{ft})$ from the doorway so that was the location chosen for the tests. The doorway and window were marked with anemometer measurement locations. These locations can be seen in figures 27 and 28. The measurement setup is shown in figure 24 and the inlet and outlet of the room are shown in figure 25 .

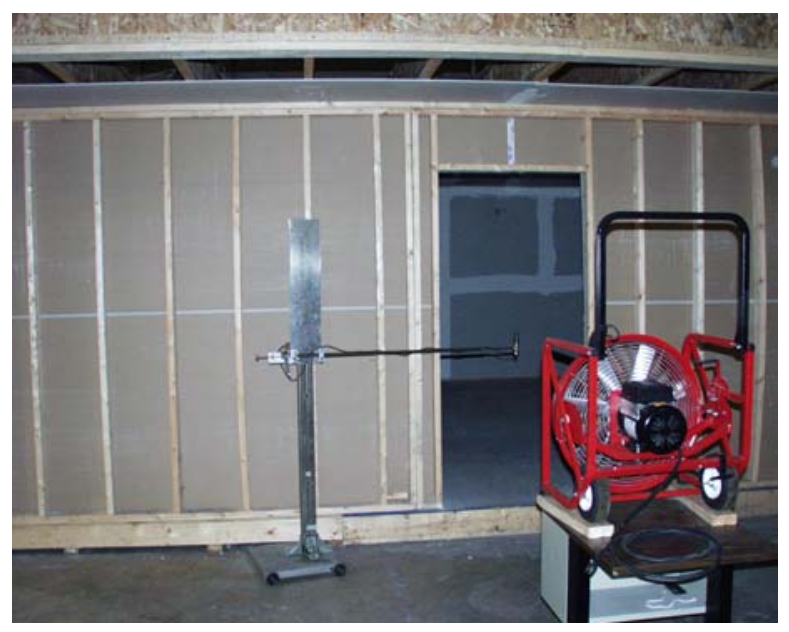

Figure 24. Experimental layout for phase II.

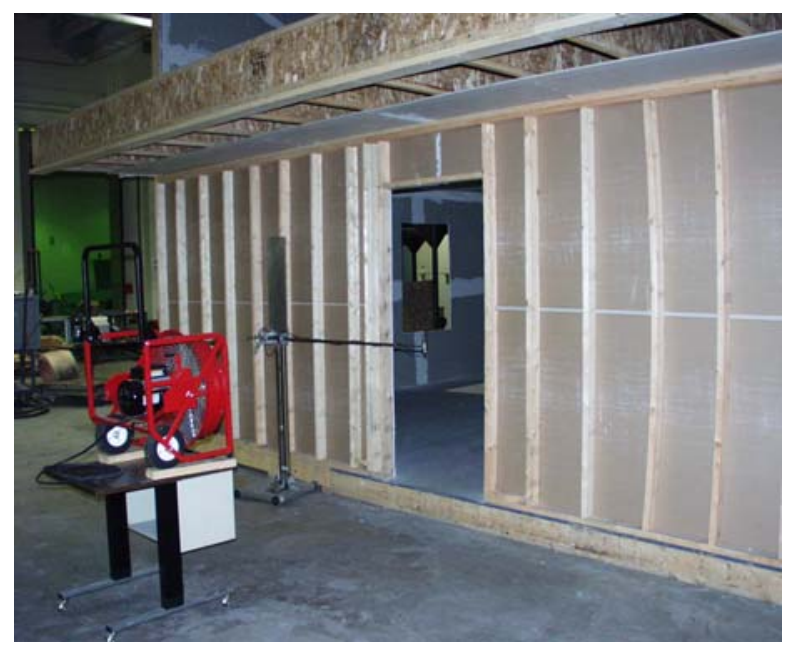

Figure 25. Experimental layout looking at room inlet and outlet. 


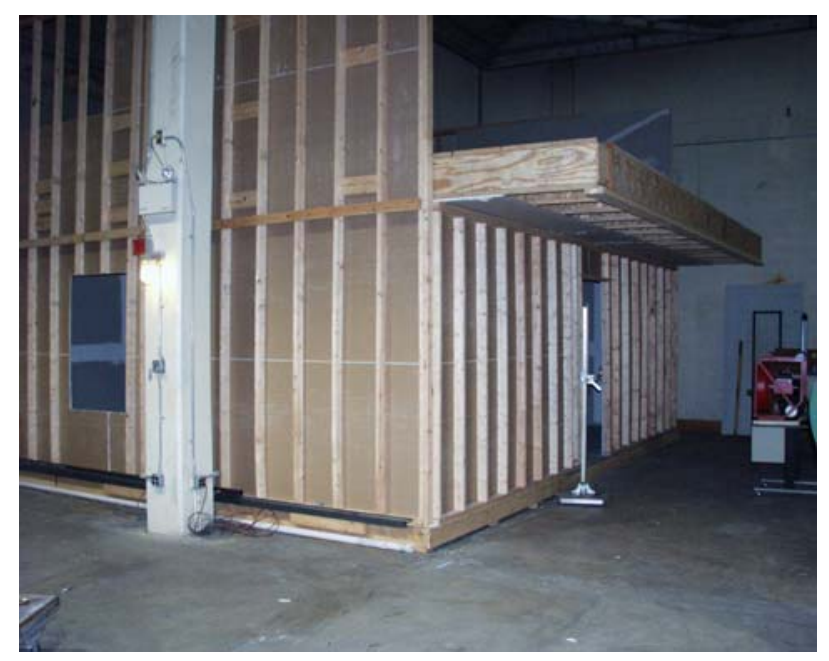

Figure 26. Inlet and outlet from a different perspective.

\subsubsection{Experimental Procedure}

The fan was turned on and allowed to run for two minutes at maximum speed, 2200 RPM. While the fan was running, the door was rechecked to make sure there was a cone of airflow around the door, and the window was checked to make sure there was a constant flow prior to measurement. Once the fan had been running for two minutes the data recording was started. Four minutes of readings were taken without rotating the anemometer. Signals were sampled every two seconds and the signal record was the average of eight continuous samples. Readings were taken at specific points at the door and window as seen in figures 27 and 28 in order to record the air flow through the room.

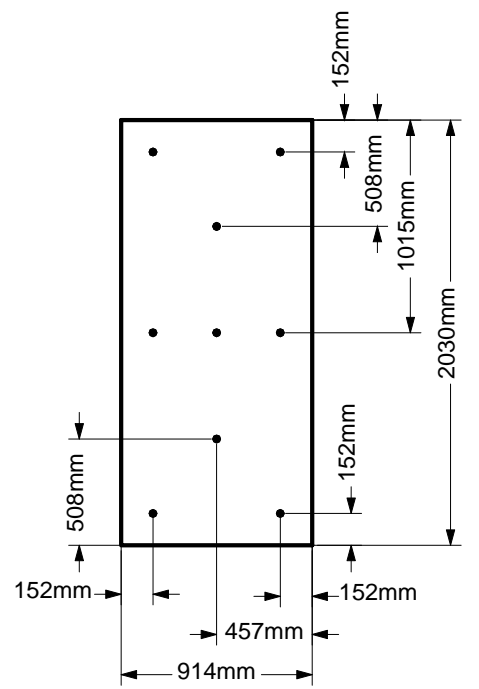

Figure 27. Phase II measurement points in the doorway (inlet). 


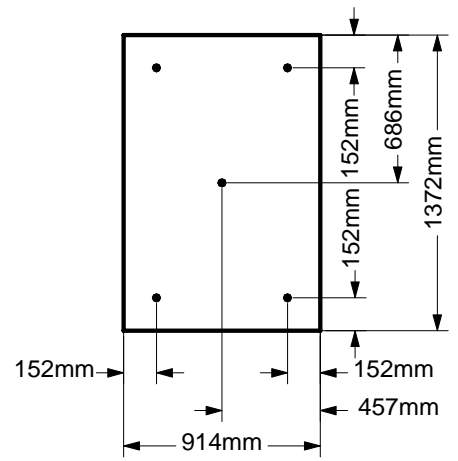

Figure 28. Phase II measurement points in the window (outlet).

\subsubsection{Flow Visualization Experiment}

In order to visualize and qualify the flow through the room a supplemental experiment was performed. A smoke generator was placed in the room and turned on to produce enough simulated smoke in order to fill the room. Cameras were set up and the fan was turned on to the maximum, $2200 \mathrm{rpm}$. Pictures were taken of the simulated smoke flow from the room on a black background to be compared to the FDS simulations. See figures 29 and 30.

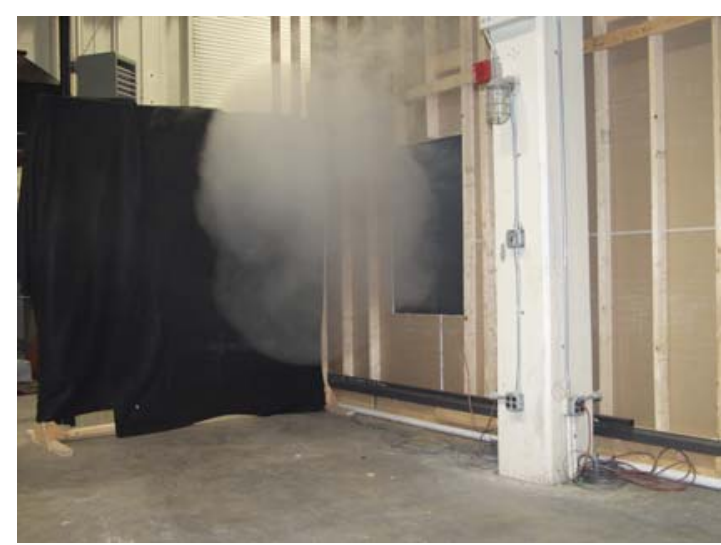

Figure 29. Visualization of Phase II supplemental experiment as soon as room is pressurized. 


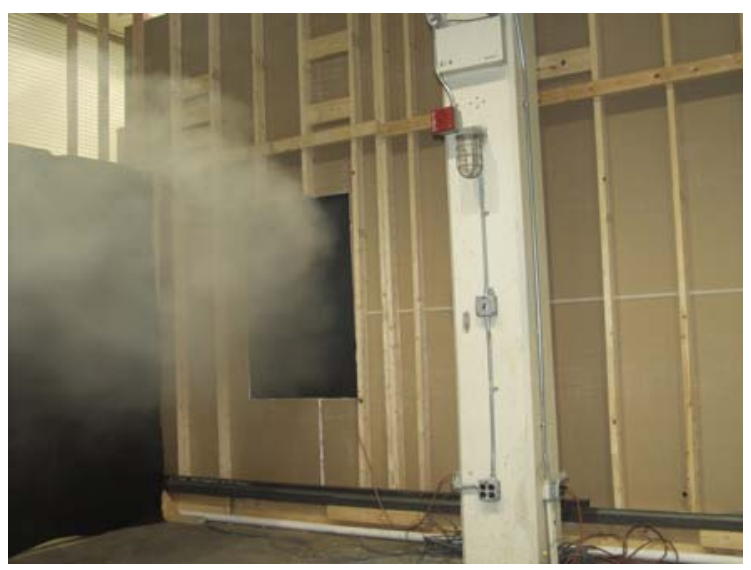

Figure 30. Visualization of phase II once constant flow is achieved.

\subsection{Computer Model}

\subsubsection{FDS Input}

The inputs required by FDS in order to model the PPV fan for this experiment were the same as those in phase I. The difference was the addition of the room. The room required additional inputs such as the properties of the ceiling, walls and openings.

\subsection{1a Geometry and Vents}

The PPV fan used for these runs was the same fan created in phase I. (See section 2.2.3a for details on fan geometry and vent considerations.) Phase II involved the addition of a room with dimensions of that in figures 24-26. This room was prescribed in FDS as a series of blocks with characteristics of gypsum board. The dimensions and openings were the same as those in the experimental setup. All of the room boundaries, including the walls and ceiling were contained within the domain. None of the room envelope obstructions were formed by the use of a boundary. The main issue that arises with the use of both the fan and the room is computational cell size. As stated in phase I, the fan required a computational cell size of $16.4 \mathrm{~cm}^{3}\left(1.00 \mathrm{in}^{3}\right)$. If the domain containing the fan and room were completely $16.4 \mathrm{~cm}^{3}\left(1.00 \mathrm{in}^{3}\right)$ cells then there would be in excess of 15 million cells. Past experience with FDS suggested that the amount of cells should remain less than one million cells in order to keep computer computational time down. With 15 million cells one simulation would require over a month to complete.

In order to minimize the number of cells and still maximize the accuracy of the calculation FDS has a feature entitled multiblocking. Multiblocking enables the user to save computational time by applying relatively fine grids in areas that need it and coarse grids elsewhere [8]. In this case a fine grid is used for the domain surrounding the fan and a coarser grid is used for the room. There are many considerations that need to be taken into account when using multiblock, especially for these cases due to the large quantity of air movement. The finer grid, the fan grid, must be specified first in the input file. This allows FDS to give precedence to this domain and speed up calculation times. Second, the grids need to overlap by at least one meter. This helps speed up calculations because information is transferred from grid to grid via external boundaries [8]. When 
the grids overlap they share the same information, which helps speed up calculations. Third, neither of the domain boundaries can be within one meter of the face of the fan. This allows for airflow in and out of the fan. Placing the end of a domain too close to the fan face causes a linear flow, which is not accurate. Next, the fan grid should not be embedded within the room grid. When this is done information is not transferred between the grids and there will be no results for the fan. Finally, the cell size for the room domain should not be larger than $65.6 \mathrm{~cm}^{3}\left(4.00 \mathrm{in}^{3}\right)$.

Another issue that needs to be addressed is the positioning of the PPV fan. From the Smokeview animation, it appears that the fan is floating in mid air. The reason for this is the inability of FDS to portray angled geometry. Typically the fire service places the fan away from the door and adjusts the angle of the fan to achieve a cone surrounding the opening [2]. In order for FDS to achieve this angle there would have to be hundreds of pieces prescribed to create the shroud. In order to avoid this, the fan is placed in the center of the doorway above floor level. This placement allows for the flow from the fan to complete a cone around the opening just as done by the fire service, without using hundreds of additional inputs to the model.

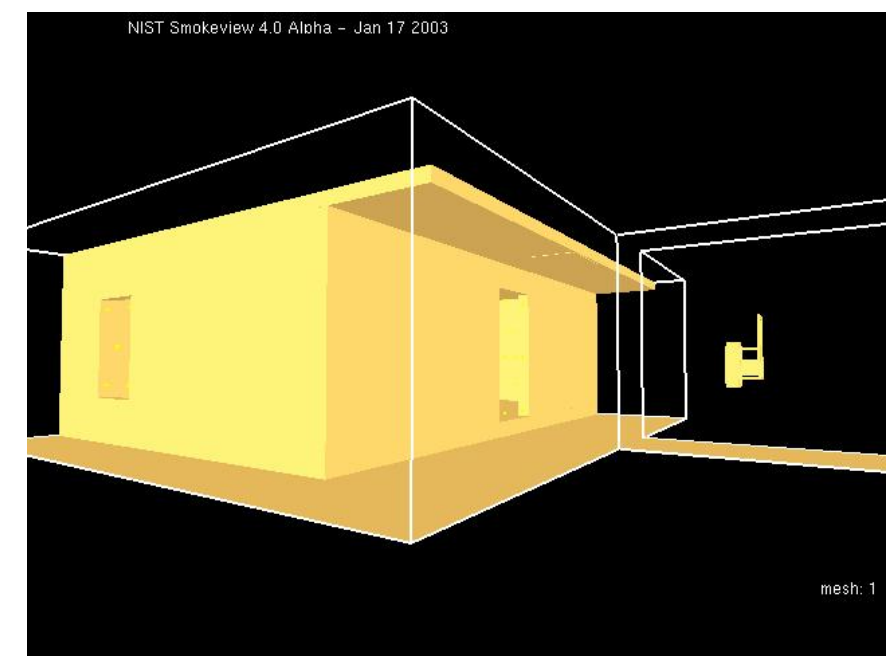

Figure 31. FDS layout for phase II.

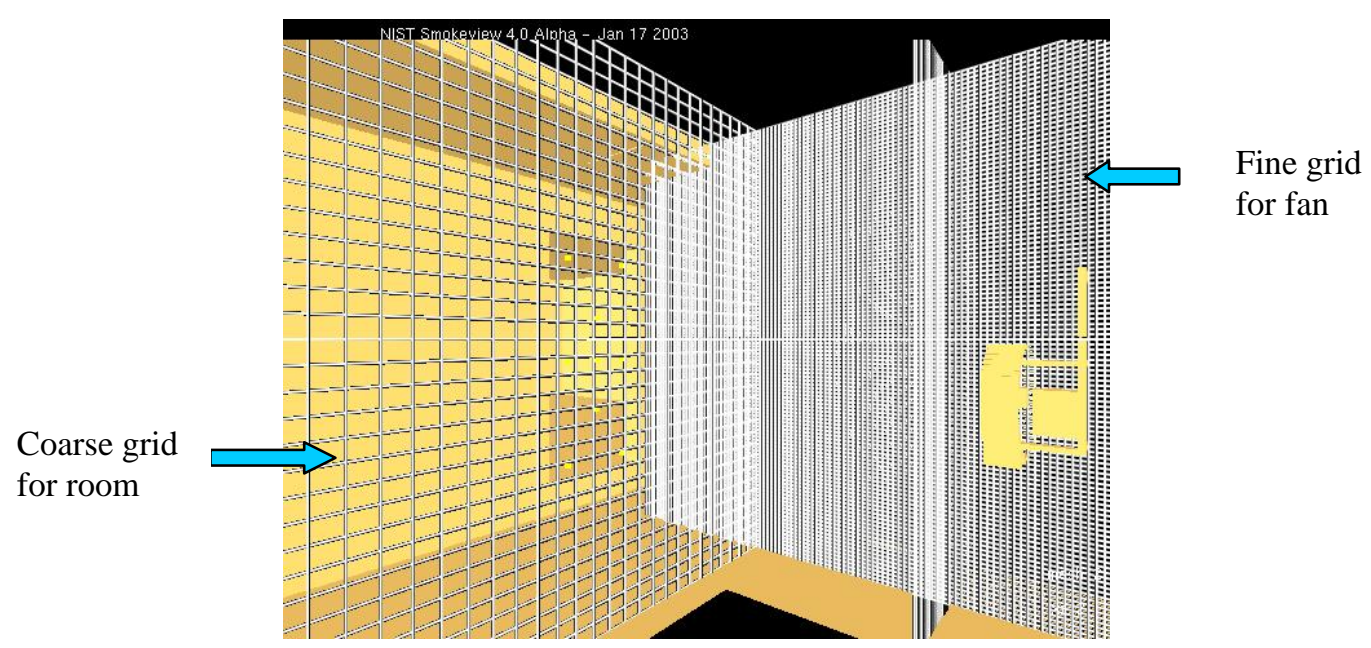

Figure 32. Grid cell visualization, multiblocking. 


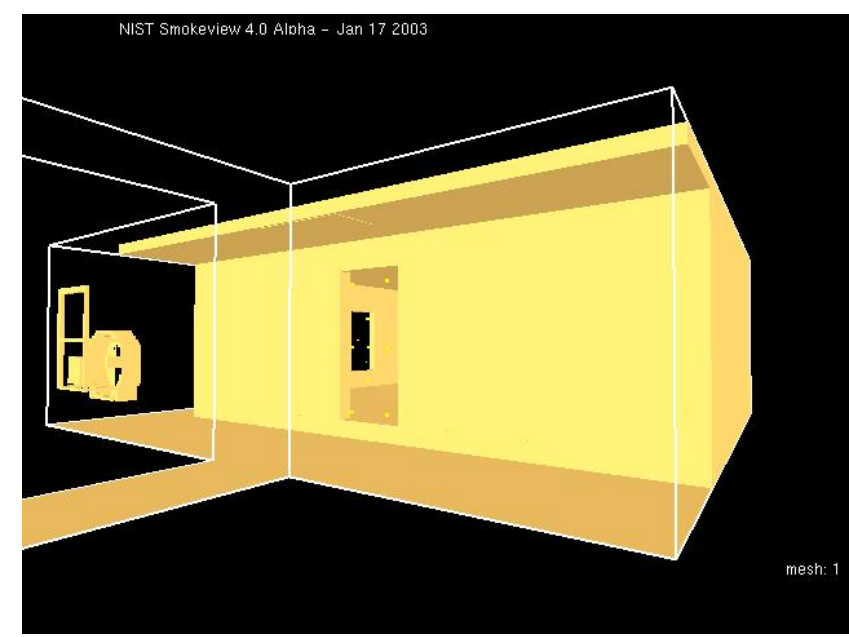

Figure 33. FDS layout looking at room inlet and outlet.

\subsection{Results}

Velocity measurements were taken at the locations in the door shown in figure 27, and in the window in figure 28. These measurements were recorded with the fan $3050 \mathrm{~mm}$ (10 $\mathrm{ft}$ ) from the front door of the room. Having the fan $3050 \mathrm{~mm}(10 \mathrm{ft})$ from the door provides a cone of air around the front door per International Fire Service Training Association recommendations [2]. The magnitudes of the velocities into the door are shown in figure 35. The magnitudes of the outlet velocities at the window are in figure 37. The average inlet velocity at the door is $2.2 \mathrm{~m} / \mathrm{s}(7.2 \mathrm{ft} / \mathrm{s})$. The average outlet velocity at the window is $2.6 \mathrm{~m} / \mathrm{s}(8.5 \mathrm{ft} / \mathrm{s})$. NIST's Fire Dynamic Simulator was used to examine the use of the PPV fan from phase I in the same configuration as in the experiment. FDS yielded an average inlet velocity at the door of $4.1 \mathrm{~m} / \mathrm{s}(13.5 \mathrm{ft} / \mathrm{s})$ and an average outlet velocity of $3.0 \mathrm{~m} / \mathrm{s}(9.8 \mathrm{ft} / \mathrm{s})$ measured at the window. These comparisons give a difference of 84 percent at the door and a difference of 16.5 percent at the window. This yields a good comparison at the window, which is the important correlation. The air movement at the window is the result of the pressure change in the room, interaction of the geometry of the room and the airflow. The door point predictions are dependent upon the local turbulence that FDS creates from the fan simulation shown in figure 34. Experimentally this turbulence is very complex and difficult to measure. Qualitatively, the flow can be compared in figures 41 to 44 .

Table 2. Comparison of Phase II Experimental and FDS Results.

\begin{tabular}{|l|c|c|}
\hline & \multicolumn{2}{|c|}{ Average Velocities (m/s (ft/s)) } \\
\hline & Door & Window \\
\hline Experimental & $2.2(7.2)$ & $2.6(8.5)$ \\
\hline Fire Dynamic Simulator & $4.1(13.5)$ & $3.0(9.8)$ \\
\hline Percent Difference & 84.0 & 16.5 \\
\hline
\end{tabular}




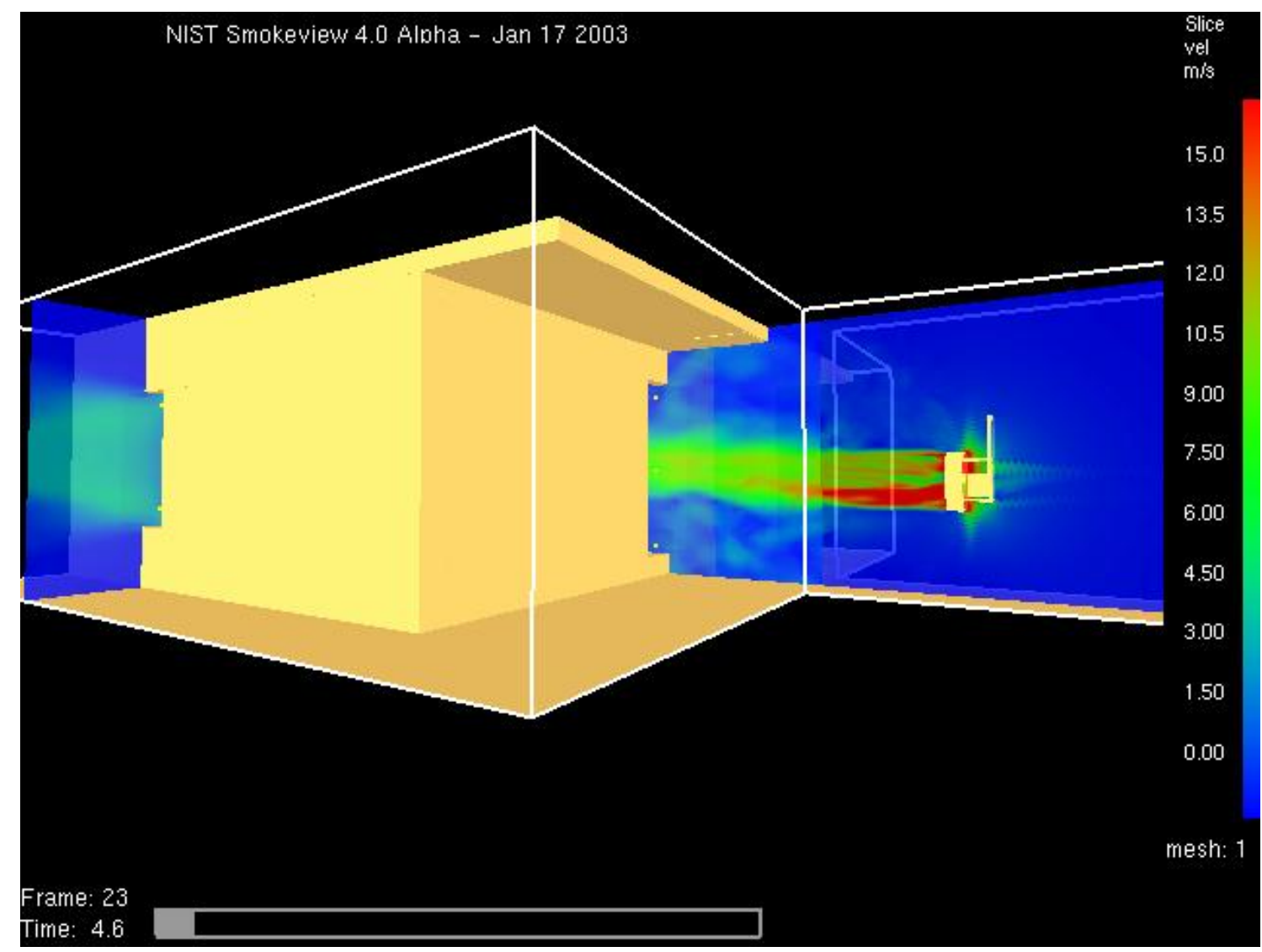

Figure 34. FDS layout with fan operating.
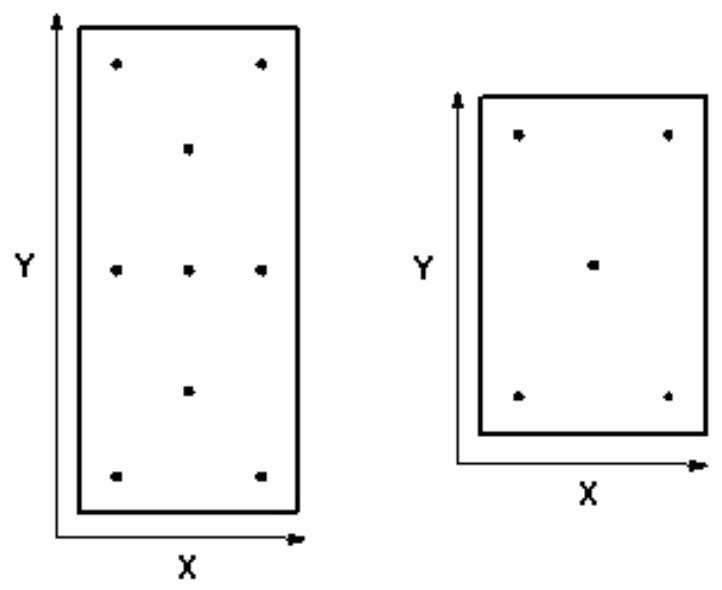

Figure 35. Orientation of velocity graphs. 


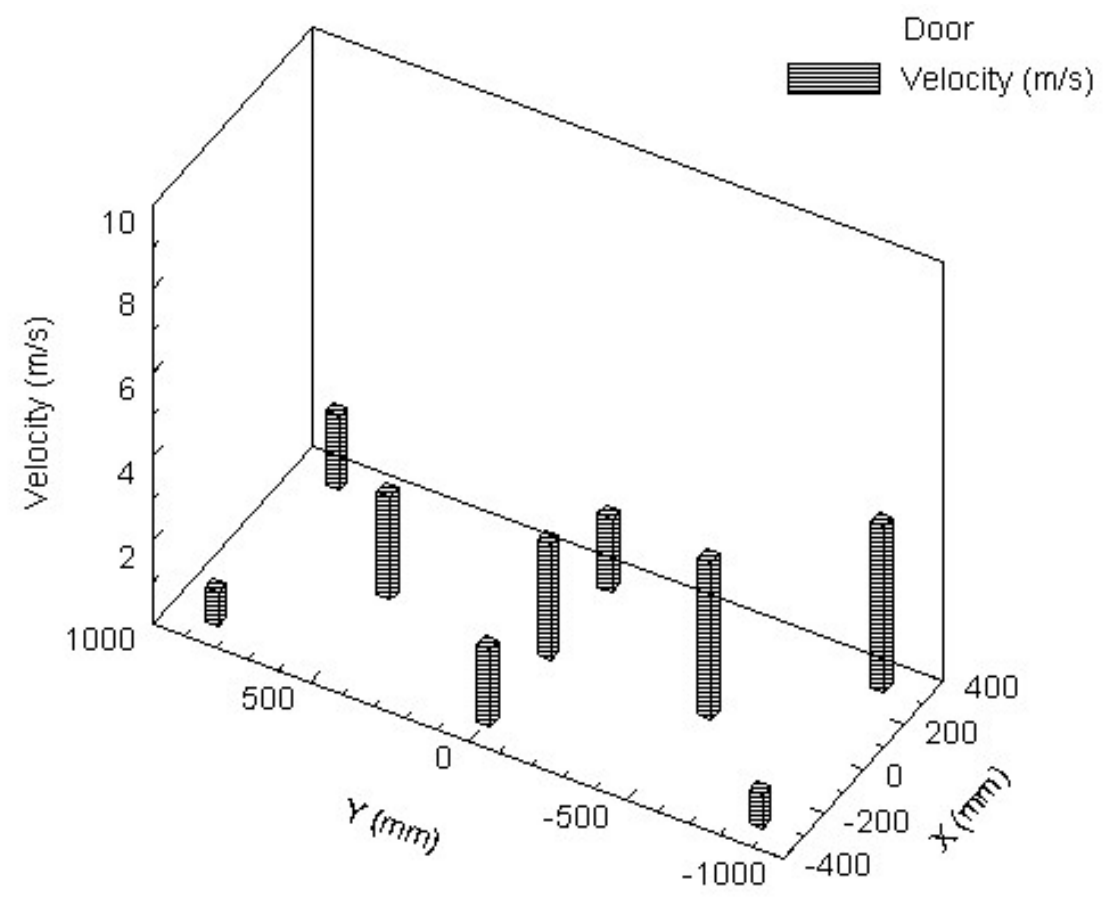

Figure 36. Experimental velocity measurements in the doorway (inlet).

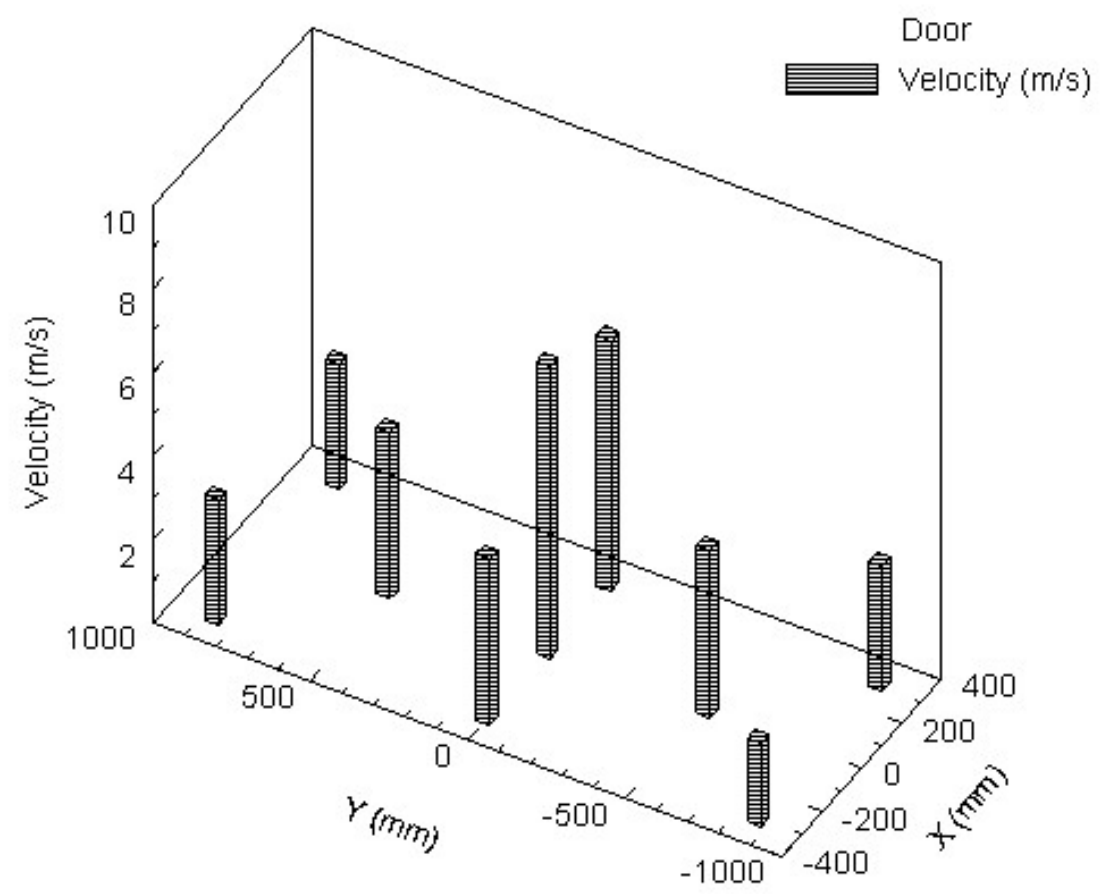

Figure 37. FDS velocities in the doorway (inlet). 


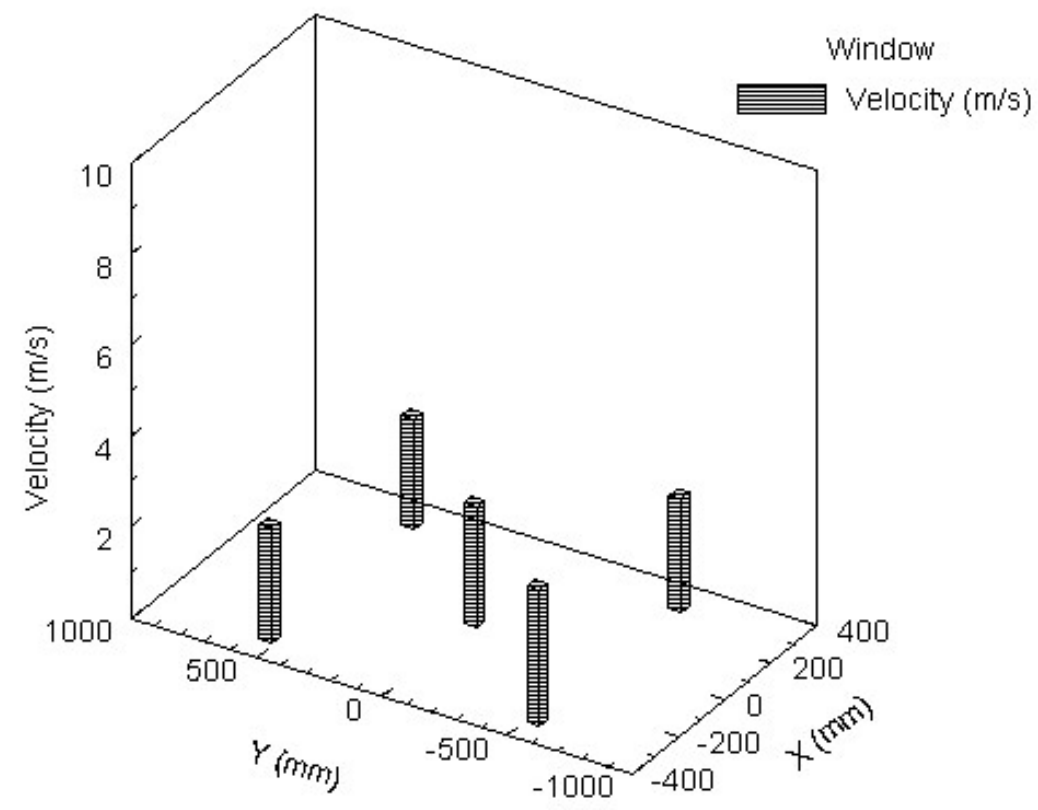

Figure 38. Experimental measurements in the window (outlet).

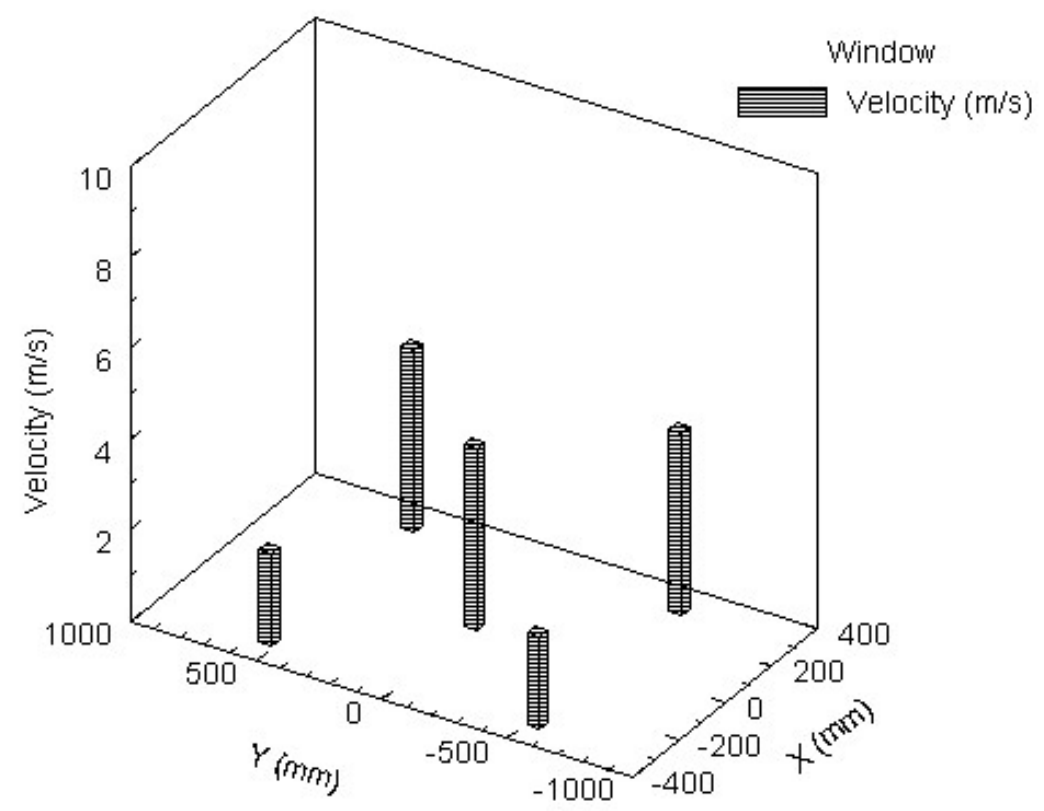

Figure 39. FDS velocities in the window (outlet). 


\section{$4 \quad$ Uncertainty}

There are different components of uncertainty in the length and velocity measurements reported here. Uncertainties are grouped into two categories according to the method used to estimate them. Type A uncertainties are those which are evaluated by statistical methods, and Type B are those which are evaluated by other means (Taylor and Kuyatt, 1994). Type B analysis of systematic uncertainties involves estimating the upper $(+\alpha)$ and lower $(-\alpha)$ limits for the quantity in question such that the probability that the value would be in the interval $( \pm \alpha)$ is essentially 100 percent.

After estimating uncertainties by either Type A or B analysis, the uncertainties are combined in quadrature to yield the combined standard uncertainty. Multiplying the combined standard uncertainty by a coverage factor of two results in the expanded

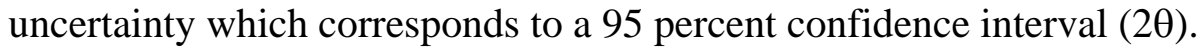

Components of uncertainty are tabulated in Table 3. Some of these components, such as the velocities, are derived from instrument specifications, while other components, such as length measurements include past experience. Each length measurement was taken carefully but due to some construction issues such as the size and straightness of the lumber, the slots for the strings on the grid having thickness, and the symmetry of the rather large room the total expanded uncertainty was estimated to $6 \%$. The flow measurements were taken in the complex flow of the positive pressure ventilation fan, which created a total expanded uncertainty of $14 \%$ primarily due to the repeatability and the randomness of the measurements.

Table 3. Uncertainty in Experimental Data

\begin{tabular}{|l|c|c|c|}
\hline & & $\begin{array}{c}\text { Combined Standard } \\
\text { Uncertainty }\end{array}$ & $\begin{array}{c}\text { Total Expanded } \\
\text { Uncertainty }\end{array}$ \\
\hline Length Measurements & $\pm 1 \%$ & & \\
$\quad$ Grid Size & $\pm 0.5 \%$ & & \\
String Location & $\pm 0.5 \%$ & $3 \%$ & $6 \%$ \\
Fan Stand Height & $\pm 1 \%$ & & \\
Anemometer Location & $\pm 1 \%$ & & \\
Fan Location & $\pm 1 \%$ & & \\
Room Dimensions & $\pm 2 \%$ & & \\
Repeatability & $\pm 2 \%$ & & \\
Random & $\pm 0.5 \%$ & & \\
& $\pm 5 \%$ & & \\
\hline Flow Measurements & $\pm 5 \%$ & & \\
Calibration & & \\
Repeatability & & & \\
Random & & & \\
\hline Note: Random and repeatability evaluated as Type A, other components as Type B & \\
\hline
\end{tabular}




\section{Discussion}

A comparison of the computational fluid dynamic model Fire Dynamic Simulator (FDS) was made with data from two different sets of data collected from full-scale experiments. The full-scale experiments characterized a Positive Pressure Ventilation (PPV) fan in an open atmosphere, and with a simple room geometry. Both experimental data sets provide insight into the gas velocities, as well as providing the opportunity to validate the predictions of the Fire Dynamic Simulator.

The measurements for the fan in an open atmosphere compared favorably with the FDS predictions. With the correct geometry, vent placement and boundary location FDS predicted velocities that were within 10 percent of the experimental results. FDS's visualization of the flow pattern also correlates well with the experimental visualization.

The measurements for the fan and a single room also compared favorably with the FDS predictions for the flow out the window. The flow that was created out of the window in FDS was within 20 percent of that measured experimentally. FDS's visualization of the flow out of the window also correlates well with that measured experimentally.

The results from these two experiments are a good indicator that FDS is able to accurately portray the flow created by positive pressure ventilation fans. Future experiments need to be conducted to examine the flow in other structures such as a multifloor structures and structures with a more complex geometry. The impact of the fan on other factors in the fire environment such as temperature, burning rate, and gas concentrations should be examined in future studies.

\section{Table 4. Summary of FDS Fan Characteristics Recommended for Efficient Effective Modeling.}

\begin{tabular}{|l|l|}
\hline 1 & Computational cell size of less than or equal to $16.4 \mathrm{~cm}^{3}\left(1.00 \mathrm{in}^{3}\right)$ \\
\hline 2 & At least 1 meter of domain to the rear of the fan \\
\hline 3 & Shroud must be cylindrical \\
\hline 4 & Vents must be located on the front face of the shroud \\
\hline 5 & A velocity must be prescribed for the vents (17.88 $\mathrm{m} / \mathrm{s}$ for this fan) \\
\hline 6 & $\begin{array}{l}\text { A block must be added to the center of the shroud to simulate the blade center } \\
\text { (effects air movement) }\end{array}$ \\
\hline 7 & A motor must be added to the rear of the fan (effects air movement) \\
\hline
\end{tabular}

Table 5. Recommended Multiblock Characteristics For an Accurate Flow Calculation.

\begin{tabular}{|l|l|}
\hline 1 & Specify the fan grid (finer) first in the data file \\
\hline 2 & Overlap the grids by at least 1 meter \\
\hline 3 & Neither of the domain boundaries should be within 1 meter of the fan \\
\hline 4 & Do not embed on grid within the other \\
\hline 5 & $\begin{array}{l}\text { Computational cell size for the non-fan grid should not be greater than } 65.6 \mathrm{~cm}^{3} \\
\left(4.00 \text { in }^{3}\right)\end{array}$ \\
\hline
\end{tabular}




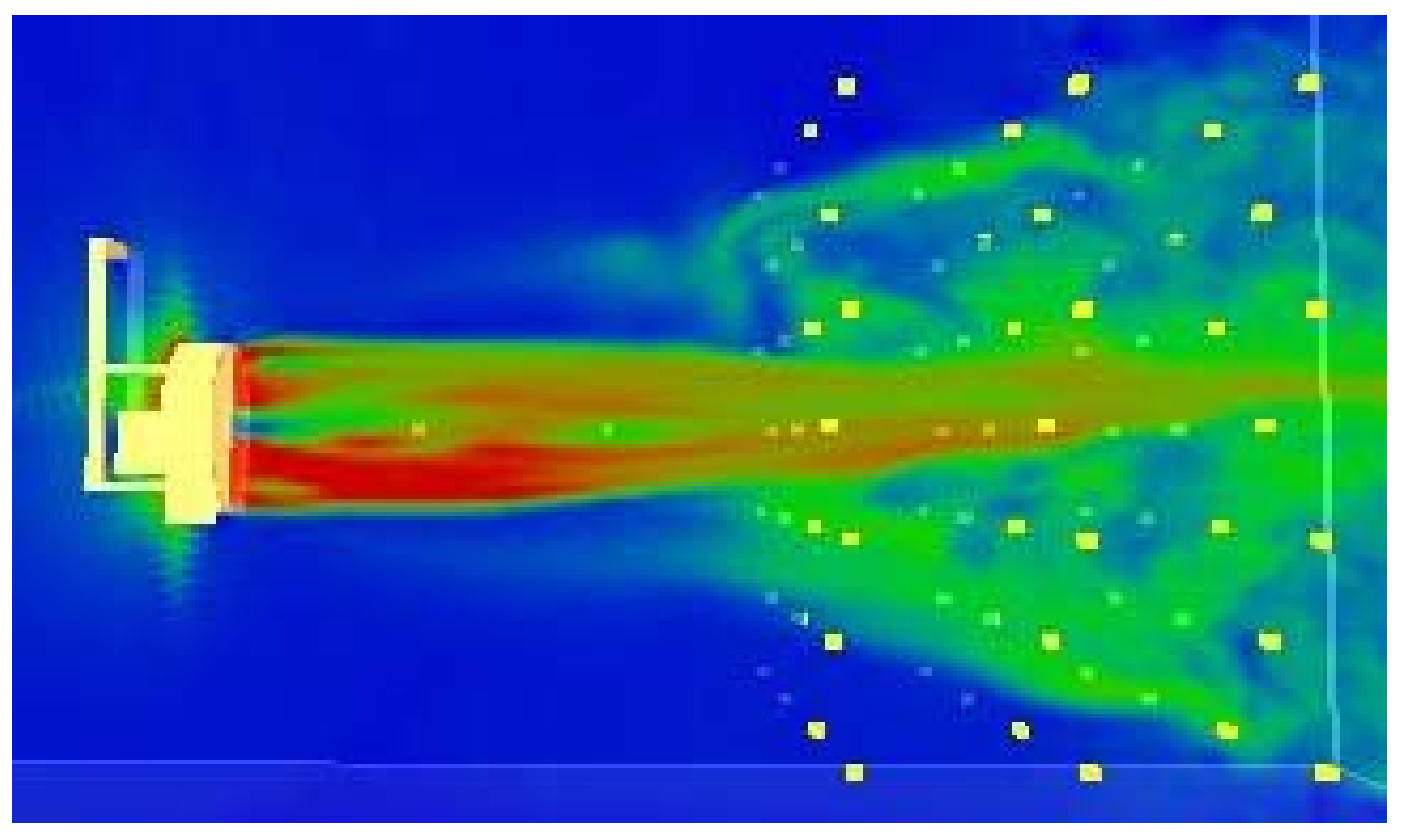

Figure 40. Smokeview visualization of FDS PPV flow pattern.

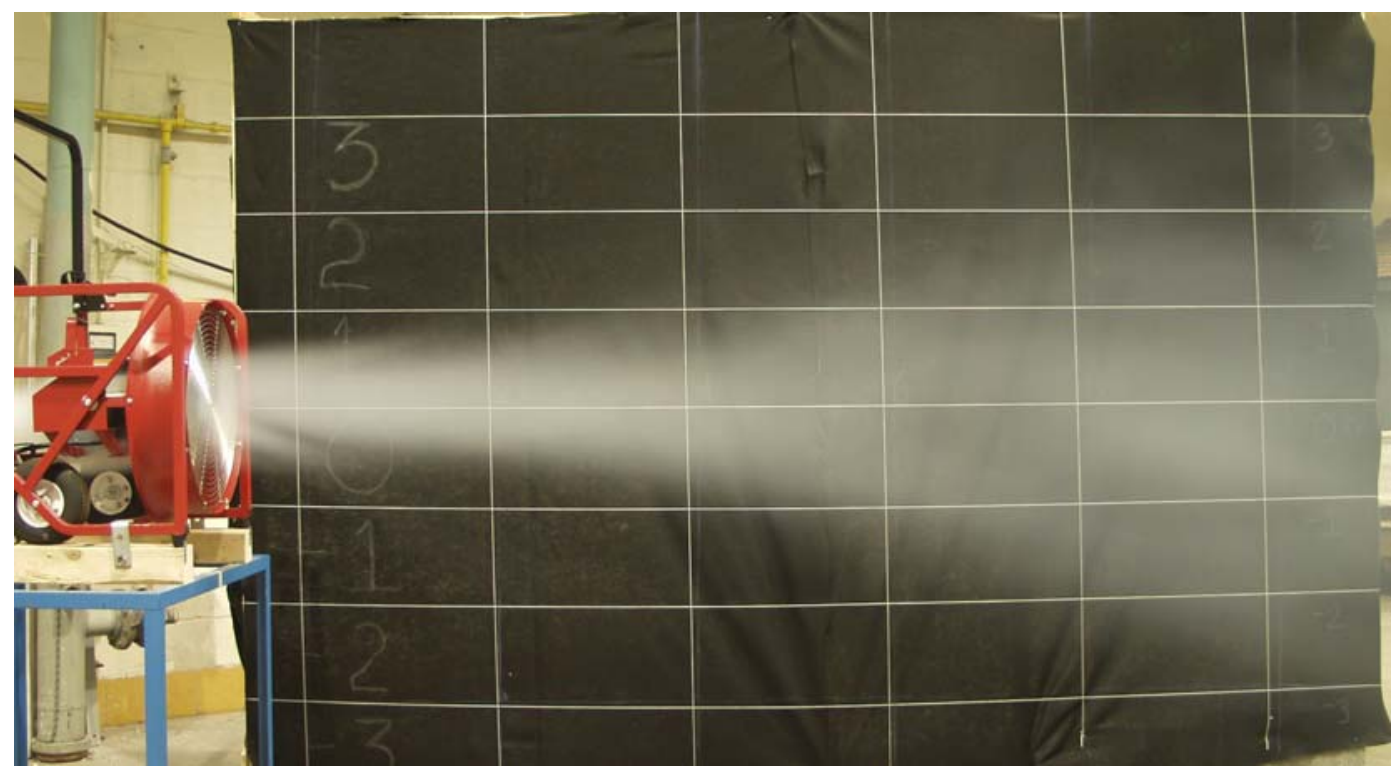

Figure 41. Experimental visualization of the PPV flow pattern. 


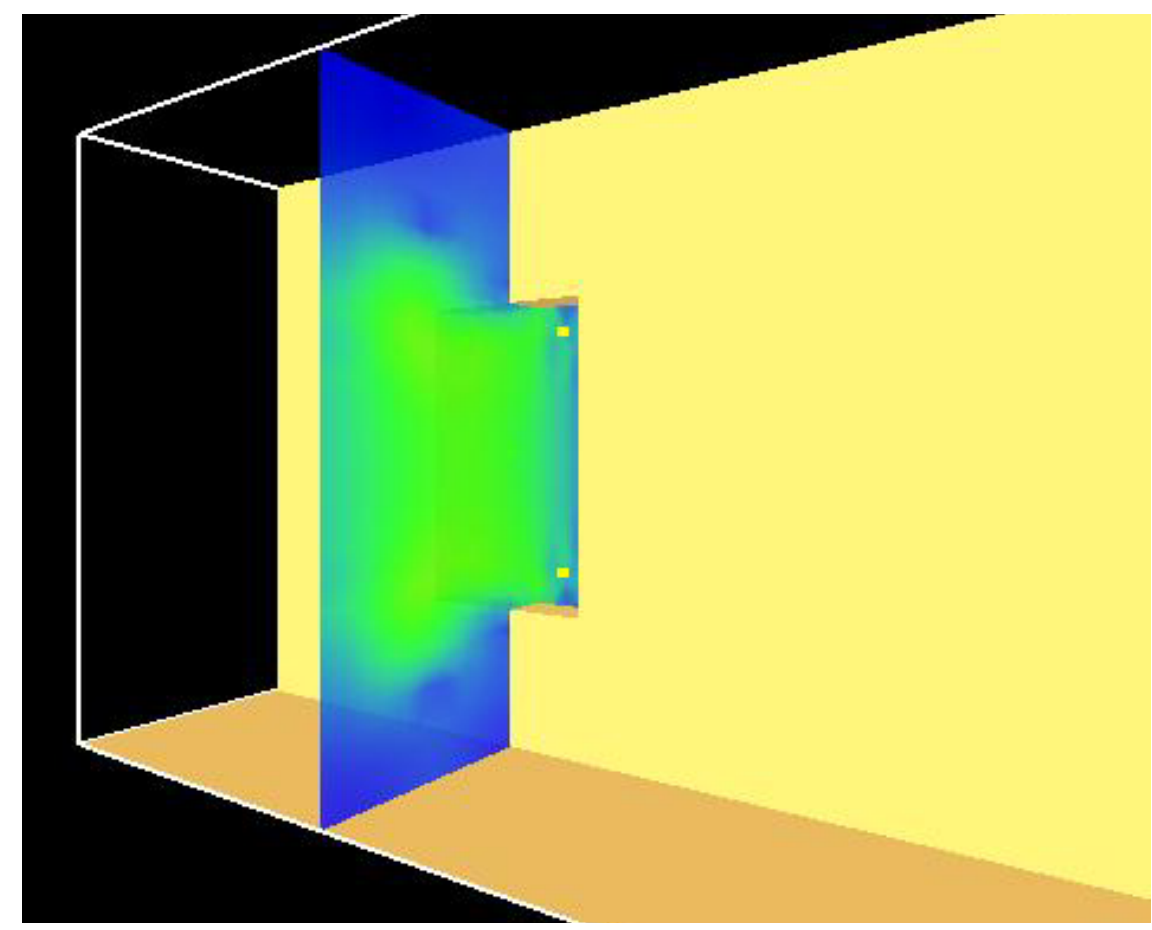

Figure 42. FDS visualization of Phase II supplemental experiment as soon as the room is pressurized.

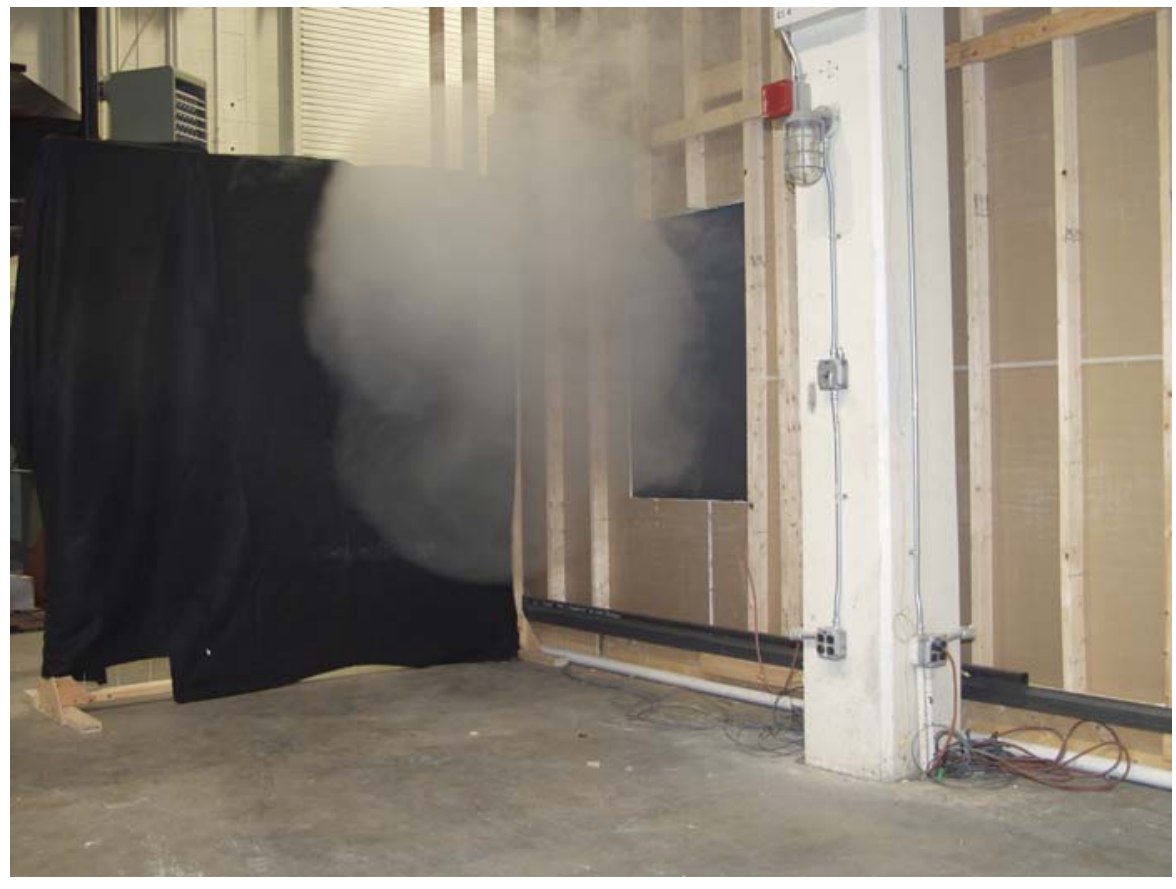

Figure 43. Visualization of Phase II supplemental experiment as soon as the room is pressurized. 


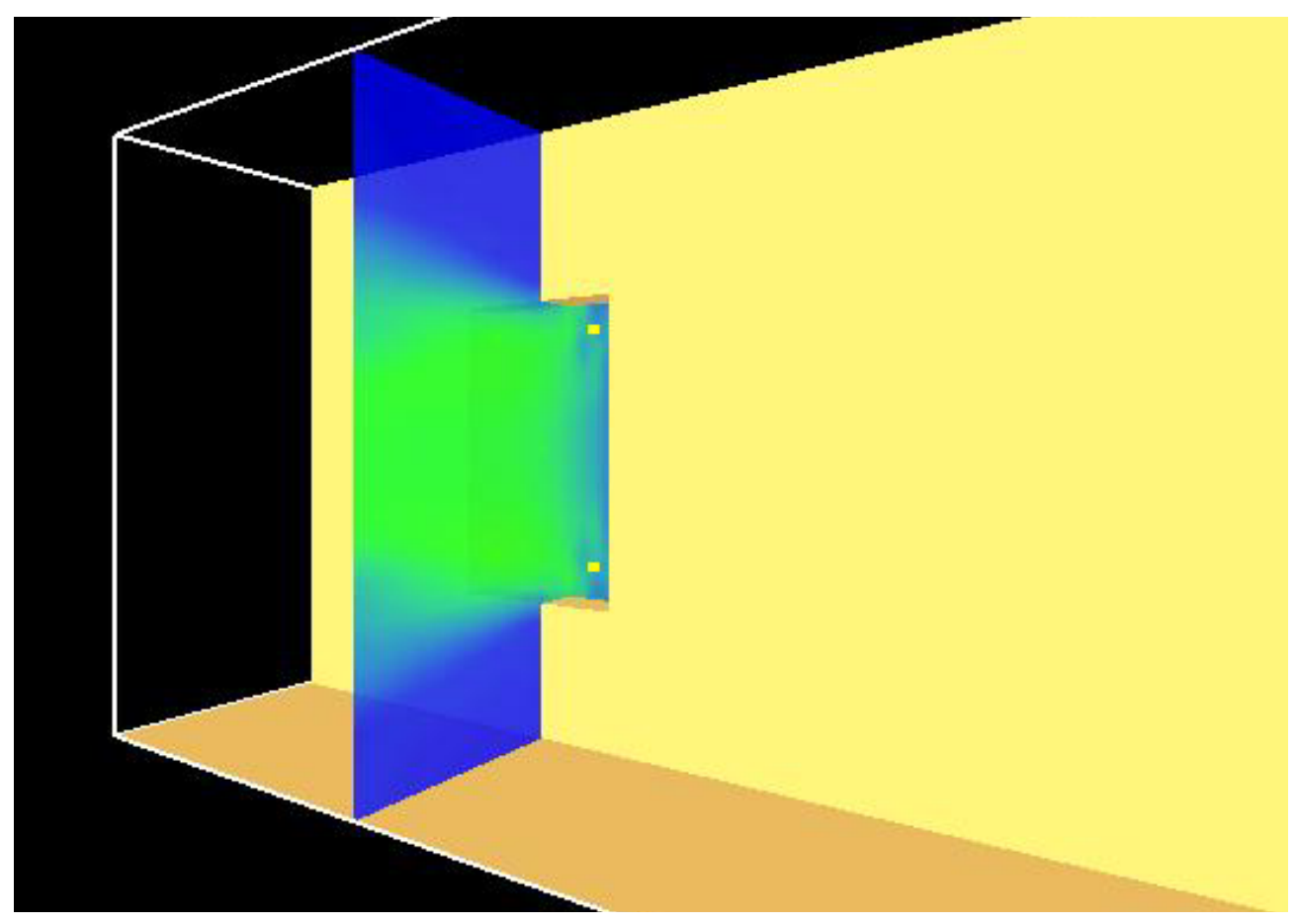

Figure 44. FDS visualization of phase II once constant flow is achieved.

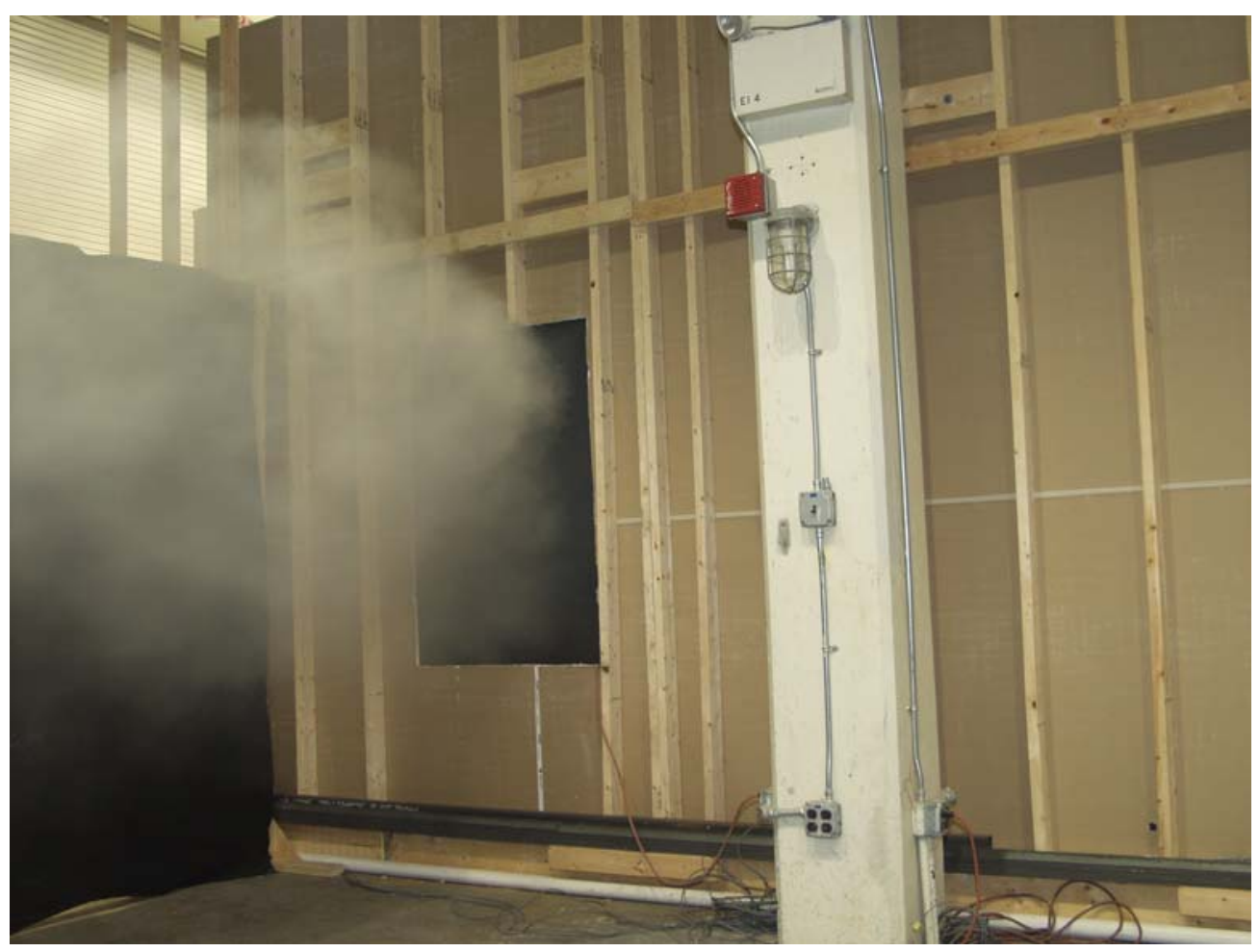

Figure 45. Visualization of phase II once constant flow is achieved. 


\section{References}

1. Walton, William D., Bryner, Nelson, Madrzykowski, Daniel, Lawson, James R., Jason, Nora H., Fire Service Needs Workshop Proceeding - San Antonio, Texas, October 13-15, 1999. National Institute of Standards and Technology, Gaithersburg, MD., NISTIR 6538, July 2000.

2. Hall, Richard, Adams, Barbara, Essentials of Fire Fighting, $4^{\text {th }}$ ed., Oklahoma State University, Stillwater, OK., 1998.

3. Tempest Technology Corporation, http://www.tempest-edge.com, January 2003.

4. Omega Engineering Inc., User’s Guide for the HH-31A Handheld Anemometer, Stamford, CT, 1996.

5. Mcgrattan, Kevin B., Baum, Howard R., Rehm, Ronald G., Hamins, Anthony, Forney, Glenn P., Fire Dynamics Simulator - Technical Reference Guide, National Institute of Standards and Technology, Gaithersburg, MD., NISTIR 6467, January 2000.

6. Mcgrattan, Kevin B., Baum, Howard R., Rehm, Ronald G., Large Eddy Simulations of Smoke Movement, Fire Safety Journal, vol 30 (1998), p 161-178.

7. Mcgrattan, Kevin B., Hamins, Anthony, Stroup, David, Sprinkler, Smoke \& Heat Vent, Draft Curtain Interaction - Large Scale Experiments and Model Development, National Institute of Standards and Technology, Gaithersburg, MD., NISTIR 6196-1, September 1998.

8. Mcgrattan, Kevin B., Forney, Glenn P., Fire Dynamics Simulator - User's Manual, National Institute of Standards and Technology, Gaithersburg, MD., NISTIR 6469, Rev. 1, May 2002.

9. Super Vacuum Manufacturing Company, Inc., http://www.supervac.com, January 2003.

\section{$7 \quad$ Acknowledgements}

Appreciation is extended to Dan Madrzykowski, Kevin Mcgrattan and Glenn Fourney of the Building and Fire Research Laboratory for their technical assistance. In addition, I would like to thank Bill Twilley and Roy McLane for their support with setting up and running the experiments. Finally I would like to thank Robert T. McCarthy of the United States Fire Administration for his support of this project. 
